\title{
Impacts of Saharan Dust on Atlantic Regional Climate and Implications for Tropical Cyclones $\mathscr{}$
}

 \\ XidAn Feng, ${ }^{\text {a JONATHAN H. JiAnG, }}{ }^{\mathrm{c}}$ YUK L. YUnG, ${ }^{\mathrm{b}}$ AND RENYI ZHANG ${ }^{\mathrm{a}}$ \\ ${ }^{a}$ Department of Atmospheric Sciences, Texas A\&M University, College Station, Texas \\ ${ }^{\mathrm{b}}$ Division of Geological and Planetary Sciences, California Institute of Technology, Pasadena, California \\ ${ }^{\mathrm{c}}$ Jet Propulsion Laboratory, California Institute of Technology, Pasadena, California
}

(Manuscript received 27 October 2016, in final form 19 June 2018)

\begin{abstract}
The radiative and microphysical properties of Saharan dust are believed to impact the Atlantic regional climate and tropical cyclones (TCs), but the detailed mechanism remains uncertain. In this study, atmosphereonly simulations are performed from 2002 to 2006 using the Community Atmospheric Model, version 5.1, with and without dust emission from the Sahara Desert. The Saharan dust exhibits noticeable impacts on the regional longwave and shortwave radiation, cloud formation, and the convective systems over West Africa and the tropical Atlantic. The African easterly jet and West African monsoon are modulated by dust, leading to northward shifts of the intertropical convergence zone and the TC genesis region. The dust events induce positive midlevel moisture and entropy deficit anomalies, enhancing the TC genesis. On the other hand, the increased vertical wind shear and decreased low-level vorticity and potential intensity by dust inhibit TC formation in the genesis region. The ventilation index shows a decrease in the intensification region and an increase in the genesis region by dust, corresponding to favorable and unfavorable TC activities, respectively. The comparison of nondust scenarios in 2005 and 2006 shows more favorable TC conditions in 2005 characterized by higher specific humidity and potential intensity, but lower ventilation index, wind shear, and entropy deficit. Those are attributable to the observed warmer sea surface temperature (SST) in 2005, in which dust effects can be embedded. Our results imply significant dust perturbations on the radiative budget, hydrological cycle, and large-scale environments relevant to TC activity over the Atlantic.
\end{abstract}

\section{Introduction}

Atmospheric aerosols profoundly impact cloud and precipitation processes (IPCC 2013; Zhang et al. 2015). For example, light scattering and absorption of the solar radiation by aerosols influence the atmospheric stability through cloud thermodynamics, convective development, and direct radiative forcing (Fan et al. 2007a; R. Zhang et al. 2007; Fan et al. 2008; Li et al. 2008a, 2009; Wang et al. 2013, 2014a,b; Peng et al. 2016). Also, by serving as cloud condensation nuclei $(\mathrm{CCN})$ or ice nuclei (IN), aerosols modify cloud microphysical processes, which affect the cloud properties (i.e., lifetime, albedo, vertical extent, and fraction), precipitation efficiency,

Supplemental information related to this paper is available at the Journals Online website: https://doi.org/10.1175/JCLI-D-160776.s1.

Corresponding authors: Renyi Zhang, renyi-zhang@neo. tamu.edu; Yuan Wang, yuan.wang@caltech.edu and lightning activities (Nesbitt et al. 2000; Orville et al. 2001; Rosenfeld et al. 2008; Li et al. 2008b; Wang et al. 2011). Presently, the direct and indirect effects by aerosols represent the largest uncertainty in projection of future climate by anthropogenic activity (IPCC 2013; Wu et al. 2016; Wang et al. 2018).

Dust, as one of the major natural aerosol types, exerts broad impacts on regional climate and the Earth energy balance (IPCC 2013). A range from 1000 to 4000 teragrams $(\mathrm{Tg})$ of dust is injected into the atmosphere on an annual basis (Zender et al. 2004; Huneeus et al. 2011), and about $500 \mathrm{Tg}$ is deposited in the ocean (Kaufman et al. 2005; Shao et al. 2011). The natural and anthropogenic dust sources account for $75 \%$ and $25 \%$, respectively, of the total emissions (Ginoux et al. 2012). In

Publisher's Note: This article was revised on 7 march 2022 to Correct the affiliation of coauthor Feng and to amend the incorrect attribution of support for lead author Pan that was originally published in the Acknowledgments. 
the semiarid area of North Africa, the mean column burdens of anthropogenic and natural dust are 0.21 and $0.20 \mathrm{~g} \mathrm{~m}^{-2}$, respectively, where the anthropogenic dust emission accounts for $51 \%$ of the local dust emission (Guan et al. 2016). Of the estimated $1150 \mathrm{Tg}$ of dust particles lifted annually from the Saharan desert, approximately $25 \%$ are transported westward to the Atlantic Ocean (d'Almeida 1986; Kaufman et al. 2005; Schepanski et al. 2009; Shao et al. 2011). There are still large uncertainties in the estimations of regional or global dust emissions. Using radon-222 as a long-range-transport tracer, Prospero and Carlson (1970) found that the Saharan dust is transported across the Atlantic Ocean within a period of a week. Saharan dust emission exhibits a strong seasonal cycle with the heaviest emission during boreal summer (Kaufman et al. 2005), which is in phase with the active season for African easterly waves (AEWs) and the Atlantic hurricane season from June to November.

Dust particles directly absorb and scatter solar radiation and perturb the atmospheric vertical temperature profile (Huang et al. 2015), causing cooling at the surface but warming aloft (Carlson and Benjamin 1980; Chen et al. 2010). It has been shown that the relative importance of the absorption and scattering properties of dust particles plays an important role in the determination of the regional radiative budget that perturbs the regional climate (Strong et al. 2015). The radiative effects of dust stabilize the atmosphere and suppress convective development (Wong et al. 2009). Lau and Kim (2007a) have found that dust attenuation of the solar radiation (i.e., the dust dimming effect) accounts for $30 \%-40 \%$ of the observed SST change over the Atlantic Ocean between 2005 and 2006. Wong et al. (2008) have shown that a positive SST anomaly increases the temperature at $850 \mathrm{hPa}$, which strengthens the anticyclonic flow at $700 \mathrm{hPa}$ through the thermal wind balance and modifies the dust outflow from West Africa and the downwind SST. The resulting SST variation subsequently triggers a series of feedbacks on the atmosphere-ocean system, altering the large-scale circulation and perturbing the regional climate and tropical cyclone (TC) activities (Evan et al. 2006). Furthermore, recent modeling studies have shown that the dust radiative effect enhances the rainfall and increases cloudiness of the east Atlantic ITCZ, but reduces the precipitation and cloud fraction over the west Atlantic and Caribbean region (Lau et al. 2009). Dust also perturbs the large-scale flow (e.g., AEWs) and precipitation associated with the West African monsoon (Lau et al. 2009; Kim et al. 2010; Wilcox et al. 2010) and weakens the westerly flow of the West African monsoon (Yoshioka et al. 2007).

In addition to the radiative effect, dust particles also serve as CCN, IN, and giant CCN (GCCN) that modify the cloud macro- and microstructures and further perturb the hydrological cycle and cloud radiative forcing (Seigel et al. 2013). Although less water soluble compared to sea salt, dust can activate as CCN (Karydis et al. 2011; Logan et al. 2014), especially when coated with sulfate and organic species (Logan et al. 2014). Numerous $\mathrm{CCN}$ suppress the growth of raindrops and precipitation efficiency due to the inhibited collision and coalescence process (Rosenfeld et al. 2001; Fan et al. 2007b; Lin et al. 2016). In addition, the condensational heat released from water vapor increases the updraft velocity in convective systems, which enhances the surface precipitation efficiency in the mixed-phase clouds yet decreases the accumulated surface precipitation (van den Heever et al. 2006). Moreover, previous modeling and observational studies have suggested that dust particles coated with sulfate during transportation over polluted regions can serve efficiently as GCCN (Levin et al. 1996; van den Heever et al. 2006). An increased GCCN concentration enhances the collision and coalescence processes (Posselt and Lohmann 2008) and increases the warm precipitation rate (Levin et al. 1996; Rosenfeld and Nirel 1996; Yin et al. 2000; Yuan et al. 2008). On the other hand, Lohmann (2002) and Cziczo et al. (2004) have shown that mineral dust serves efficiently as IN. DeMott et al. (2003) have demonstrated that the IN concentration within the dust layer is two orders of magnitude higher than the typical median concentration of IN. Dust acting as IN further influences the precipitation initiation, cloud lifetime, cloud-scale dynamics, and cloud radiative effect (Prenni et al. 2009).

The aerosol impacts on TCs have been an active research topic since Project Stormfury from 1962 to 1983 (Willoughby et al. 1985). Rosenfeld et al. (2012) have shown that aerosols invigorate convection and strengthen the downdraft, by cutting off the air spirals into the center of TCs and weakening the TC development. Wang et al. (2014c) have illustrated that anthropogenic aerosols profoundly impact TCs; the coupled microphysical and radiative effects of anthropogenic aerosols result in delayed development, weakened intensity, and early dissipation of TCs, but an enlarged rainband and increased precipitation under polluted conditions. Saharan dust has been shown to play an important role in perturbation of the TC activities over the Atlantic Ocean. H. Zhang et al. (2007) have evaluated the influence of Saharan dust as CCN on the development of idealized TCs using the Regional Atmospheric Modeling System (RAMS) and found that dust induces variations in the hydrometeor properties, modifying the storm diabatic heating distribution, thermodynamic structures, and dynamical responses. The mean sea level pressure (MSLP) at the peak intensity 
increases by about $25 \mathrm{hPa}$ in the dust-polluted case $\left(2000 \mathrm{~cm}^{-3}\right)$, as a result of invigorated precipitation in the rainband (H. Zhang et al. 2007; Zhang et al. 2009). On the other hand, the dust radiative effect increases the static stability of the atmosphere and reduces the upward moisture flux from the lower to middle troposphere, leading to a lesser conductive atmosphere for TC genesis (Reale et al. 2014). Using an atmospheric general circulation model (ECHAM6), Bretl et al. (2015) have shown that the radiative properties of dust increase vertical wind shear but decrease moisture in the lower troposphere, both inhibiting the genesis of TCs.

The atmospheric and oceanic conditions (i.e., SST, atmospheric temperature, and moisture) are the key factors that determine the hurricane activities (Arguez et al. 2007). The year of 2005 with 28 named storms represented one of the most active hurricane seasons over the past decades, including the devastating Hurricane Katrina (Beven et al. 2008), whereas the 2006 Atlantic hurricane activity was rather near average with 10 tropical storms and no hurricane landfalls (Franklin and Brown 2008). Several previous studies have provided possible explanations for the different hurricane activities between 2005 and 2006. Franklin and Brown (2008) suggested that the development of El Niño in the late summer of 2006 likely enhanced the subsidence over the western Atlantic basin, which fostered an unfavorable condition for the genesis of TCs. On the other hand, Lau and Kim (2007b) have found a positive anomaly of dust loading and indicated a robust negative correlation between the dust-loading and Atlantic SST in 2006. The cooling of SST by dust in 2006 likely triggered a series of atmospheric responses to suppress the hurricane activities. In addition, dust can act as CCN and IN (Fan et al. 2014), changing the cloud microphysics and macrophysics in TCs. Moreover, the dust radiative effect could alter the regional radiative budget and change the large-scale environment (Zhao et al. 2011) and TC activities.

In this study, we perform simulations over a 5 -yr (2002-06) period using the National Center for Atmospheric Research (NCAR) Community Atmospheric Model, version 5.1, (CAM5.1) driven by the observed SST. Model evaluations over the tropical Atlantic are performed by comparing the aerosol optical depth (AOD) and precipitation between the observations and simulations. By comparison of the dust and nondust simulations, we evaluate the dust impacts on the regional climate and discuss the implications for TC genesis over the tropical Atlantic. Specifically, the model results are analyzed for the dust impacts on hydrological cycle, radiative budget, and large-scale environmental conditions relevant to TC activities. In addition, an examination of the nondust scenarios between the 2005 and 2006 seasons provides insights into the impacts of the climate states (i.e., SST variation) on the regional climate and hurricane activities.

\section{Methodology}

CAM5.1 is the atmospheric component of the stateof-art Community Earth System Model and contains an active community land model (CLM), a thermodynamiconly sea ice model (CICE), and a data ocean model (DOCN) using the prescribed monthly climatological SST from 1850 to 2008 (Neale et al. 2010). The performance of CAM5.1 has been previously evaluated (Ghan et al. 2012; Park et al. 2014; Wang 2015; Wang et al. 2016). The SST and sea ice concentration data are from the merged HadISST optimal interpolation (OI) dataset prior to 1981 and the Smith/Reynolds EOF dataset post1981 ranging from January 1850 to March 2009 (Neale et al. 2010). Simulations using CAM5.1 are performed from 2002 to 2006 with a $1.9^{\circ} \times 2.5^{\circ}$ horizontal resolution and 30 vertical layers in the sigma-coordinate. The greenhouse gas (GHG) concentrations are represented by the global annual mean values until the end of 2005 and are identical for the years of 2005 and 2006. The anthropogenic aerosol emission data are those of the IPCC AR5 by Lamarque et al. (2010), which covers the monthly emission data in the period from 1850 to 2005. The anthropogenic aerosol emission beyond 2005 is prescribed as the 2005 level. Black carbon and organic carbon emissions are represented similarly to those by Bond et al. (2007) and Junker and Liousse (2008). Sulfur dioxide emission is from Smith et al. (2001, 2004). The emission of $\mathrm{NH}_{3}$ is prescribed from the Model for Ozone and Related Chemical Tracers version 4 (MOZART-4) dataset (Emmons et al. 2010). The emission of sea salt follows Mårtensson et al. (2003), where the emission is determined by wind speed and water temperature.

The aerosol representations have been significantly improved in CAM5.1, capable of simulating important aerosol processes, including aerosol nucleation, coagulation, condensational growth, gas and liquid phase chemistry, emission, dry deposition, and wet deposition (Liu et al. 2012). The aerosol properties are simulated by the three-mode version of the Modal Aerosol Model (MAM3) and categorized into the accumulation, Aitkin, and coarse modes. Aerosol is assumed to be internally mixed in each size mode and externally mixed among the different modes. Dust is internally mixed with primary and secondary organic matter, black carbon, and sea salt in the accumulation mode, and mixed with sea salt and sulfate in the coarse mode in the MAM3. The size of each aerosol mode is assumed to follow the lognormal distribution 
with a prescribed geometric deviation in each mode (Easter et al. 2004).

The dust emission and transportation are calculated based on the Dust Entrainment and Deposition Module (DEAD) (Zender et al. 2003) in the CLM (Mahowald et al. 2006). The dust emission is dominated by the sandblasting processes, which is represented by the total dust vertical mass flux $F_{j}\left(\mathrm{~kg} \mathrm{~m}^{-2} \mathrm{~s}^{-1}\right)$ in Eq. (1):

$$
F_{j}=T S f_{m} \alpha Q_{s} \sum_{i=1}^{I} \mathbf{M}_{i j}
$$

where $T$ is a global tuning factor that equals $5 \times 10^{-4}, S$ is the source erodibility factor, which is set to 1 , and $f_{m}$ represents the grid cell fraction of exposed bare soil, which is determined by the surface coverage of lake, wetland, snow, and vegetation cover. Also, $\alpha\left(\mathrm{m}^{-1}\right)$ is the sandblasting mass efficiency, which is determined by the fraction of clay in the soil; $Q_{s}$ represents the total horizontal saltating dust mass flux, which is determined by environmental surface wind friction velocity and the friction velocity threshold for dust particles; and $\mathbf{M}_{i j}$ is a $3 \times 4$ matrix representing the mass fraction that maps from three source bins to four transported bins in the CLM. The four-bin transported modes are 3.8\% $0.1-1.0 \mu \mathrm{m}$, $11 \% 1-2.5 \mu \mathrm{m}, 17 \% 2.5-5 \mu \mathrm{m}$, and $67 \% 5.0-10 \mu \mathrm{m}$ in calculation of the dust vertical mass flux (Grini and Zender 2004). The dust flux is partitioned into two of the three modes (accumulation mode $0.1-1.0 \mu \mathrm{m}$ and coarse mode $1.0-10 \mu \mathrm{m}$ ) in the MAM3 when the dust flux outputs from the CLM to the CAM.

Clouds in CAM are categorized into three groups by their cloud-top pressure (CTP) based on the International Satellite Cloud Climatology Project (ISCCP): high clouds $(\mathrm{CTP}<440 \mathrm{hPa})$, middle clouds $(440 \mathrm{hPa}<$ CTP $<680 \mathrm{hPa}$ ), and low clouds $(\mathrm{CTP}>680 \mathrm{hPa}$ ) (see Fig. S1 in the online supplemental material). Four types of clouds are treated using different cloud macro- and microphysical schemes, including the liquid and ice stratus and shallow and deep cumulus. Simulations of deep convection follow Zhang and McFarlane (1995) and Neale et al. (2008). The shallow convective scheme is described in Park and Bretherton (2009). The stratus cloud microphysics is simulated using the two-moment microphysics by Morrison and Gettelman (2008). This scheme accounts for the aerosol-cloud interaction, including activation of cloud droplets, precipitation processes, and explicit radiative interaction of cloud droplets (Neale et al. 2010). Heterogeneous ice nucleation is included according to Liu et al. (2007), and ice nucleation by dust accounts for deposition/ condensation (Meyers et al. 1992), contact freezing
(Young 1974), and immersion freezing for cirrus. Note that CAM5.1 only includes the aerosol-cloud interactions for stratiform clouds (Park et al. 2014).

Longwave and shortwave radiative transfer are parameterized using the Rapid Radiative Transfer Model for GCM applications (RRTMG). Both cumulus and stratus clouds are radiatively active. The dust radiative properties are according to the parameterizations by Hess et al. (1998) [i.e., the Optical Properties of Aerosols and Clouds (OPAC) database]. The dust consists of a mixture of quartz and clay minerals. Dust over desert has a single-scattering albedo of 0.888 , an asymmetry factor of 0.729 , and extinction coefficient of 0.145 at $550 \mathrm{~nm}$. The transported dust has a single scattering albedo of 0.837 , an asymmetric factor of 0.775 , and extinction coefficient of 0.064 at $550 \mathrm{~nm}$. The dust optical properties are derived from Mie calculation for each size bin. Absorption from aerosols and clouds is included in the longwave and shortwave radiations, whereas the scattering of aerosols and cloud is only accounted for the shortwave radiation. The net refraction index is estimated from the volume fractions and refraction indices of all aerosol components as well as water (Ghan and Zaveri 2007).

The dust impacts are evaluated from the differences between the dust and nondust scenarios. The dust scenario includes the online dust emission from the CLM and CAM5 physics (see Table S1 in the online supplemental material), whereas the vertical dust mass flux is turned off for the nondust scenario [i.e., when the total vertical mass flux of dust $F_{j}$ in Eq. (1) is zero]. It is worth noticing that dust effect may be embedded in the variations of the observed SST, which are prescribed as the boundary conditions of CAM5. Simulations are spun up from 1 January 2001 to 1 January 2002 and are integrated from 1 January 2002 to 30 November 2006. Each scenario consists of five ensemble members. The model ensembles are performed by introducing small temperature perturbations $\left(10^{-14} \mathrm{~K}\right)$ at the initialization of the model simulations. The ensemble simulations are analyzed by the $95 \%$ Student's $t$ test. The test results, along with the ensemble mean, are analyzed in the result section. To investigate the dust impacts on tropical cyclogenesis, two regions relevant to the TC genesis and intensification are defined following Lau and Kim (2007a) (see Fig. 1). Additional simulations with a finer $0.9^{\circ} \times 1.25^{\circ}$ horizontal resolution using CAM5.1 are performed from 2001 to 2006 without ensemble runs. The model physics components are similar to those of the coarse-resolution $\left(1.9^{\circ} \times 2.5^{\circ}\right)$ simulations. All simulations are performed on an EOS supercomputer, which is an IBM iDataPlex commodity cluster with nodes based on Intel's 64-bit Nehalem and Westmere 
(a) CAM AOD AT 550NM 2005

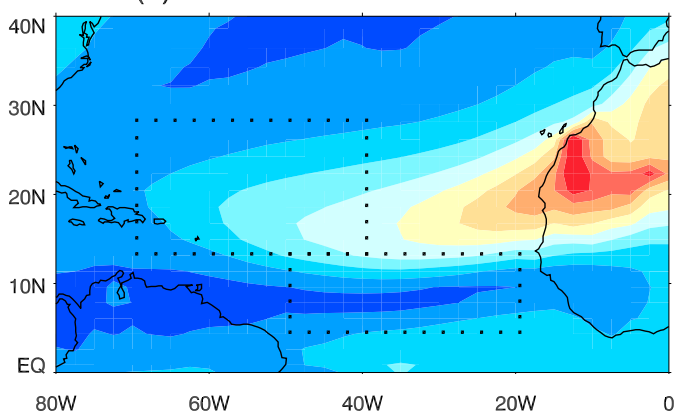

(c) MODIS AOD AT 550NM 2005

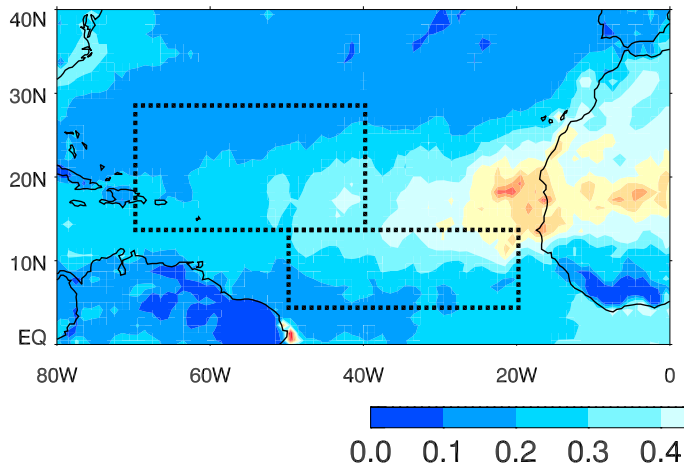

(b) CAM AOD AT 550NM 2006



(d) MODIS AOD AT 550NM 2006

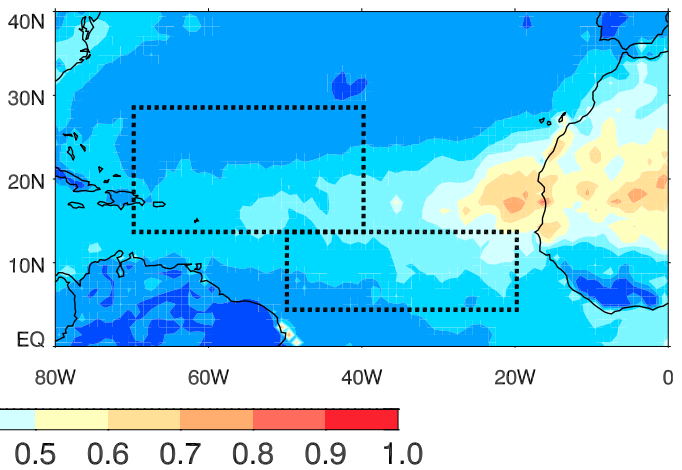

FIG. 1. AOD averaged from July to September in 2005 and 2006 from (a),(b) CAM simulations and (c),(d) MODIS observations. Locations of GNR $\left(50^{\circ}-20^{\circ} \mathrm{W}, 5^{\circ}-15^{\circ} \mathrm{N}\right.$; the bottom-right rectangular region) and ITR $\left(70^{\circ}-\right.$ $40^{\circ} \mathrm{W}, 15^{\circ}-30^{\circ} \mathrm{N}$; the top-left rectangular region), following Lau and Kim (2007a).

processor. In this paper, we focus on analyses of simulations for the periods of 2005 and 2006. To elucidate the dust impacts on the large-scale environments for TC activity, several dynamical and thermodynamic parameters are analyzed, including the midlevel wind shear, low-level vorticity, midlevel moisture, entropy deficit, potential intensity (PI), and the ventilation index (VI). In particular, the spatial average of each parameter in the TC intensification region (ITR; $70^{\circ}-40^{\circ} \mathrm{W}, 15^{\circ}-30^{\circ} \mathrm{N}$ ) and the TC genesis region $\left(\mathrm{GNR} ; 50^{\circ}-20^{\circ} \mathrm{W}, 5^{\circ}-15^{\circ} \mathrm{N}\right)$ is examined. A comparison of the nondust scenarios between 2005 and 2006 provides insight into the SST impacts on the regional climate.

\section{Results and discussion}

\section{a. Dust distribution}

Saharan dust is the dominant aerosol species over the West Africa and east Atlantic region during the boreal summer (Shao et al. 2011). Wong et al. (2009) have shown that the dust AOD contributes to $61 \%-93 \%$ of the total observed AOD over the West Africa and east Atlantic region. Thus, the AOD over West Africa and east Atlantic is employed to represent atmospheric dust loading through the extinction of solar radiation. Model simulated monthly AOD at $550 \mathrm{~nm}$ is compared with the MODIS global monthly Deep Blue (over land) and Dark Target (over ocean) AOD products (i.e., the MOD08 level 3 version 5.1 dataset) (Platnick et al. 2015). Both modeled and observed AOD are averaged from July to September in 2005 and 2006. Figures 1a and $1 \mathrm{~b}$ show the simulated ensemble mean of AOD in July, August, and September. The high MODIS AOD (greater than 0.4 ) is located to the north of $10^{\circ} \mathrm{N}$ with maximum AOD greater than 0.6 over the coastal West Africa region in the observed AOD. CAM captures the dust outflow from West Africa to the mid-Atlantic Ocean. In general, the simulated AOD in CAM is comparable to that in MODIS over the ocean. The maximum dust AOD in CAM over land is higher than that in MODIS. The differences between simulated and observed AOD are likely explained by an overestimation of the dust outflow in the Saharan region, inefficient dry deposition of fine particles (Zender et al. 2003), or overestimation of wet removal for dust (Nowottnick et al. 2011) in CAM. In contrast, the polarorbiting satellite may not capture the peak dust events that occur between the satellite overpasses, resulting in a 
(a) CAM PRECIP RATE 2005

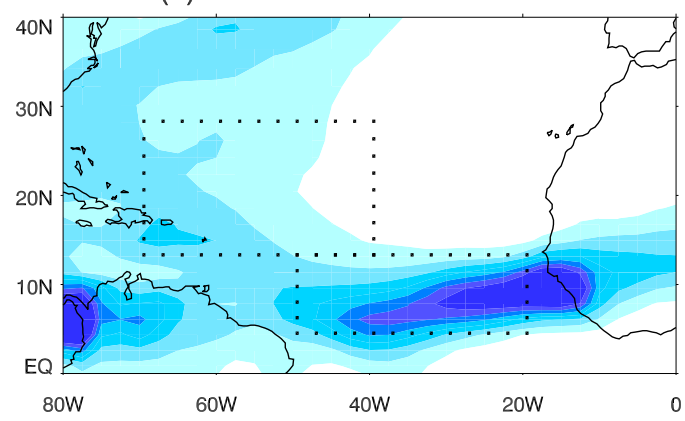

(c) GPCP PRECIP RATE 2005

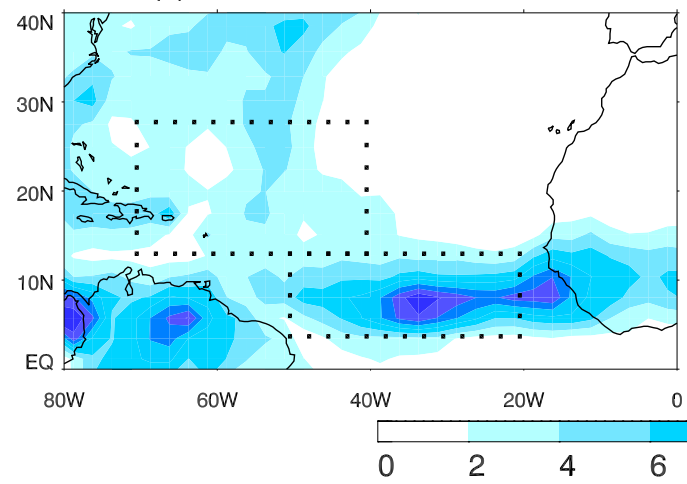

(b) CAM PRECIP RATE 2006

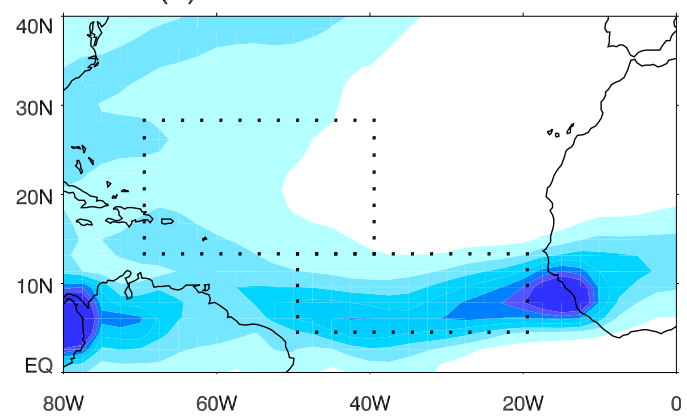

(d) GPCP PRECIP RATE 2006

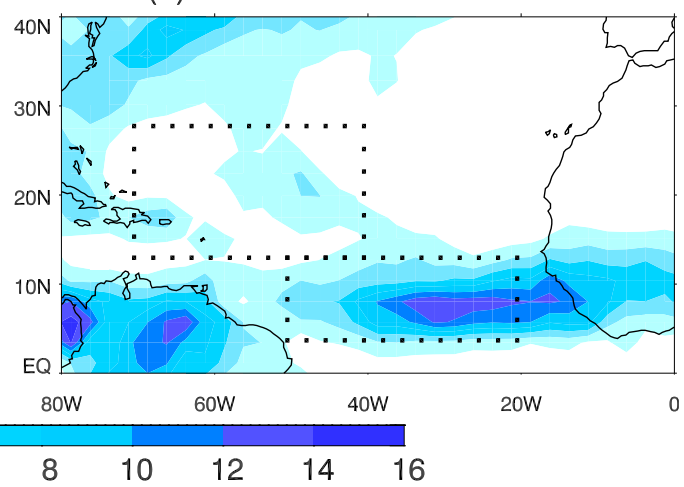

FIG. 2. Precipitation rate $\left(\mathrm{mm} \mathrm{day}^{-1}\right)$ averaged from July to September in 2005 and 2006 from (a),(b) CAM simulations and (c),(d) GPCP observations.

relatively low MODIS AOD (Ginoux et al. 2012). Also, CAM-simulated AOD over the heavy precipitation region along the ITCZ is about 0.2 lower than the MODIS AOD. Figure S2 shows the comparison between simulated and observed AOD in the ITR and GNR: the differences are within about $16 \%$ in the ITR and about $29 \%$ in the GNR, determined from the ratio of the AOD difference between the regional-averaged MODIS and CAM5 to the MODIS AOD. Nevertheless, a robust comparison of modeled and observed AOD in the GNR and ITR subregions is difficult, considering the limited sampling frequency of satellites over a smaller domain. The simulated and CALIPSO aerosol extinctions (Winker et al. 2009; CALIPSO Science Team 2015) on August of 2006 along $22^{\circ} \mathrm{W}$ are provided in Fig. S3. The geographic distributions are similar, although there are differences in the extinction values. In particular, the model successfully captures the maximum extinction values near the surface. Overall, CAM is able to capture the long-range transport of Saharan dust, especially with a reasonable performance over the ocean. Additionally, Liu et al. (2012) have provided a comprehensive evaluation on the MAM3 performance in CAM5.1. The dust concentration is calculated according to Eq. (1) and is different between 2005 and 2006. However, the differences in the monthly averaged AOD (July-September) between 2005 and 2006 over the ITR and GNR are insignificant from both model simulations (Fig. S4e) and satellite observations.

The extinction of solar radiation by dust particles is represented by the dust optical depth (DOD) in Figs. S4a and S4b. The high DOD region is located to the north of $15^{\circ} \mathrm{N}$ and further extends to the midtropical Atlantic Ocean, consistent with the dust emission and transport pathway. The maximum DOD reaches 1.0 at the source region over the western Sahara. The vertical dust distribution is represented by the dust mixing ratio cross section at $22^{\circ} \mathrm{N}$ in Figs. S4c and S4d, showing that dust accumulates in the lower troposphere and concentrates over the western Sahara $\left(20^{\circ}-10^{\circ} \mathrm{W}\right)$ region. The dust plume even reaches up to $500 \mathrm{hPa}$ and transports westward to the Caribbean region $\left(80^{\circ} \mathrm{W}\right)$.

The fine-resolution simulation of the dust mixing ratio (Figs. S5c,d) shows less dust transport westward at $700 \mathrm{hPa}$ than in the coarse-resolution simulation, possibly due to the change of model surface input data between the two resolutions. The simulated DOD (Figs. S5a,b) with fine resolution is relatively lower in the emission region than that with coarse resolution, while the spatial distribution is similar. The surface pressure with the fine-resolution simulation (Fig. S6) exhibits the same pattern as that with the 
(a) PRECL DUST 2005

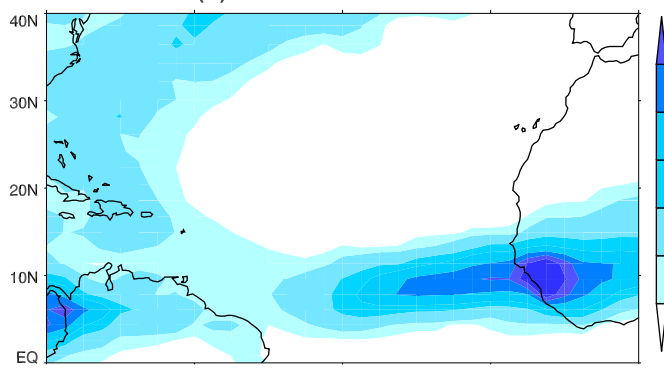

(c) PRECL DUST 2006

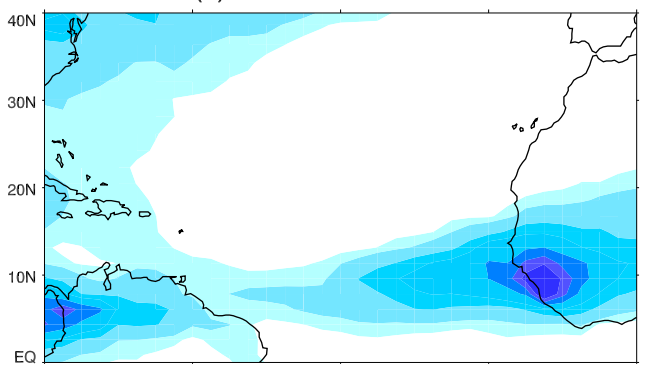

(e) PRECL D05-D06

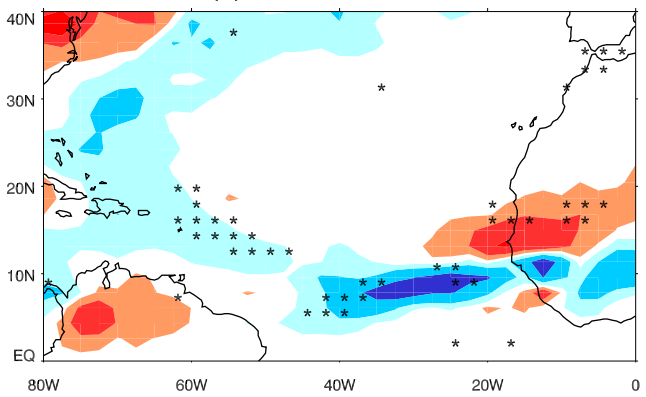

(b) PRECL D-ND 2005

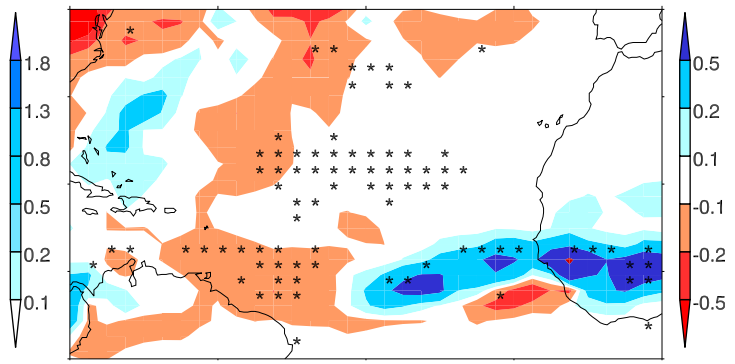

(d) PRECL D-ND 2006

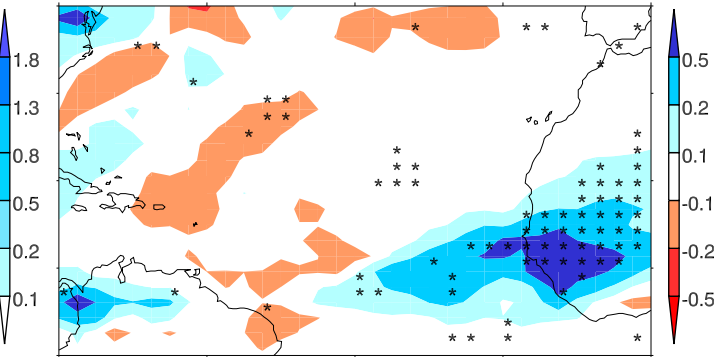

(f) PRECL ND05-ND06

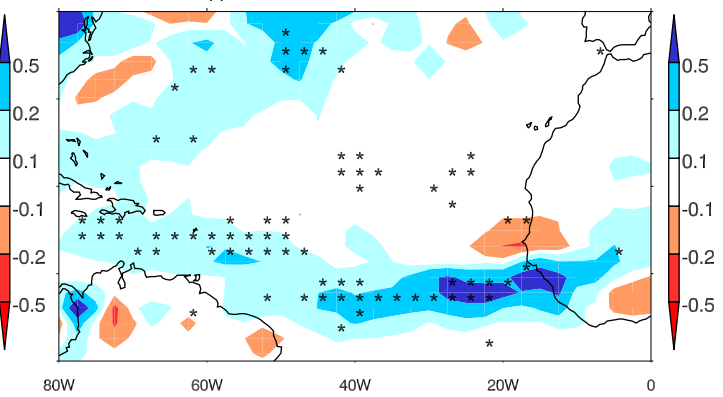

FIG. 3. Large-scale precipitation ( $\mathrm{mm} \mathrm{day}^{-1}$ ) in August (top) 2005 and (middle) 2006. (a),(c) The dust scenario. (b),(d) The difference between the dust and nondust scenarios in 2005 and 2006, respectively. (bottom) The difference between 2005 and 2006 for the (e) dust and (f) nondust scenarios. The dotted regions label the 95\% significant level of the Student's $t$ test.

coarse-resolution simulation, showing that dust both intensifies the SHL and increases the low-level moist advection over West Africa.

\section{b. Total precipitation rate}

The simulated mean precipitation rate in July, August, and September is compared with the corresponding Global Precipitation Climatology Project (GPCP) mean precipitation rate (Adler et al. 2003), as shown in Fig. 2. At $10^{\circ} \mathrm{N}$ near the West African coast, the maximum simulated precipitation rate by CAM is 14 $16 \mathrm{~mm} \mathrm{day}^{-1}$, comparable to the maximum precipitation of $10-12 \mathrm{~mm}^{-1 a y}{ }^{-1}$ from GPCP. The GPCP precipitation rates averaged spatially over GNR and ITR are 1.92 and $5.86 \mathrm{~mm} \mathrm{day}^{-1}$, compared to 2.87 and $6.6 \mathrm{~mm}$ day $^{-1}$ from simulations in 2006 . The ITCZ along $10^{\circ} \mathrm{N}$ is clearly evident from the simulations, but the precipitation rate is $1-6 \mathrm{~mm} \mathrm{day}^{-1}$ larger in CAM than that in GPCP. This difference is due to overestimations on the frequency of deep convection over land during the boreal summer and the autoconversion efficiency of deep convective clouds (Park et al. 2014). Overall, despite the differences between the simulated and observed precipitation rate, the CAM model successfully captures the precipitation distribution and the maximum precipitation region over the ITR and GNR.

We analyze the dust, SST, and the overall impacts on the various climate and TC parameters in August of 2005 and 2006. Figure 3 shows the large-scale precipitation rate, with Figs. $3 \mathrm{a}$ and $3 \mathrm{c}$ showing the large-scale precipitation rate in dust scenarios in 2005 and 2006, respectively. Figures $3 b$ and $3 d$ present the differences 
(a) DUST 2005-08

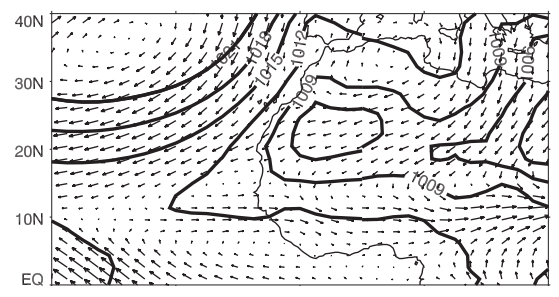

(d) DUST 2006-08

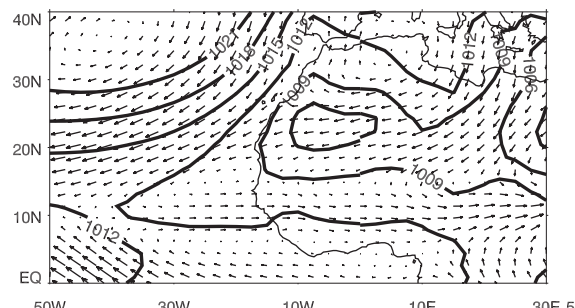

(b) NON-DUST 2005-08

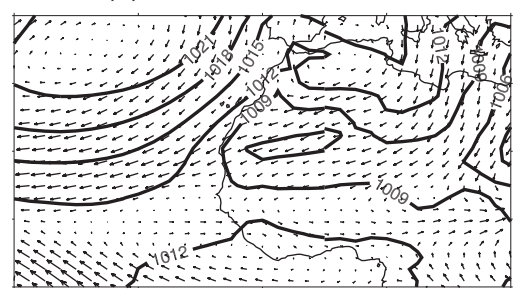

(e) NON-DUST 2006-08

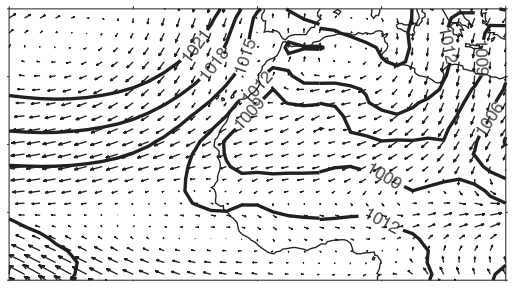

(c) DIFF 2005-08



(f) DIFF 2006-08

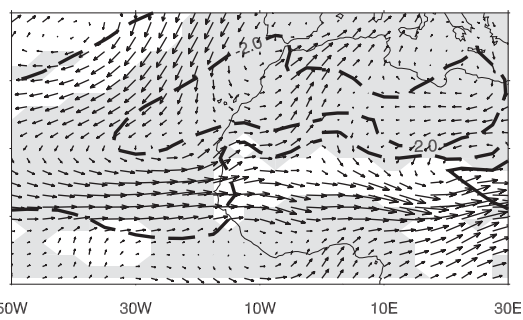

FIG. 4. Sea level pressure (hPa) and wind at $827 \mathrm{hPa}$ in August (a)-(c) 2005 and (d)-(f) 2006 for (left) the dust scenario, (center) the nondust scenario, and (right) the difference between the dust and nondust scenarios. Surface pressure contours are from 1006 to $1021 \mathrm{hPa}$ with 3-hPa intervals. The gray shaded regions in (c) and (f) represent the 95\% significance level of the Student's $t$ test.

between dust and nondust scenarios, indicating the dust impacts on the large-scale precipitation rate. Figures $3 \mathrm{e}$ and 3f show the differences between 2005 and 2006, indicating the impact of SST variations as well as the combined dust and SST impacts on the large-scale precipitation trend. The maximum large-scale precipitation is located near the coast of West Africa along $10^{\circ} \mathrm{N}$ for both the dust and nondust cases (Figs. 3a,c). Dust absorbs solar radiation and heats the troposphere, enhancing the Saharan heat low (SHL) (Fig. 4) and strengthening the westerly monsoon flow and the lowlevel moisture advection from the tropical Atlantic Ocean. The SHL corresponds to a deep, dry-convective atmospheric boundary layer (Lafore et al. 2011), which is located to the north of $20^{\circ} \mathrm{N}$ between $10^{\circ} \mathrm{W}$ and $10^{\circ} \mathrm{E}$ over the Saharan region. The strengthened westerly monsoon flow leads to an up to $1.2 \mathrm{~mm} \mathrm{day}^{-1}$ precipitation anomaly to the north of $10^{\circ} \mathrm{N}$ in the dust scenario (Figs. 3b,d). The magnitude of the negative large-scale precipitation rate anomaly is distinct in the mid-Atlantic between 2005 and 2006, indicating a high dependence on SST. In addition, the large-scale precipitation rate (Figs. 3e,f) is up to $1.2 \mathrm{~mm}$ day $^{-1}$ higher along $10^{\circ} \mathrm{N}$ in 2005 than that in 2006. The higher precipitation rate is explained because of the higher SST in 2005 (Fig. S7) that increases the atmospheric moisture content in the east Atlantic. For the combination of dust and SST effects, we found that Saharan dust (Figs. 3b,d) increases the large-scale precipitation rate along $10^{\circ} \mathrm{N}$ over the east Atlantic. Over the west Atlantic, the dust effects on the precipitation can be offset by the SST interannual variations (Fig. 3f). Saharan dust impacts the large-scale circulation and enhances the West African monsoon, consistent with a previously proposed elevated heat pump hypothesis by Lau et al. (2006). Note that the strength of the elevated heat pump is impacted by both the shortwave radiative heating and the longwave radiative cooling by dust.

Figure 5 shows the simulated convective precipitation rates for 2005 and 2006. The heavy rainband (more than $12 \mathrm{~mm} \mathrm{day}^{-1}$ ) extends westward with a decreasing trend and curving to the north across the North Atlantic Ocean. An ITCZ northward movement is evident in Figs. $5 b$ and $5 d$ because of dust, resulting in a dipole structure along the West African coast. The similar dipole structure along $10^{\circ} \mathrm{N}$ over the east Atlantic and decreasing trend in the mid-Atlantic indicate the robustness of dust impacts for 2005 and 2006 (Figs. 5b,d). In Figs. 5e and 5f, the warm SST in 2005 induces more than $4 \mathrm{~mm} \mathrm{day}^{-1}$ higher convective precipitation rate along $10^{\circ} \mathrm{N}$ toward west Atlantic than that in 2006, possibly because of the enhanced low-level convergence and African easterly jet (AEJ) in 2005 (Figs. S8c,f). However, the spatial patterns and the magnitude of the increase in convective precipitation rate in the west Atlantic due to higher SST in 2005 are likely canceled out by the suppression of the convective precipitation by dust in the west Atlantic. The cross section at $15^{\circ} \mathrm{W}$ in Fig. 6 depicts the AEJ at $600 \mathrm{hPa}$ around $15^{\circ} \mathrm{N}$, the tropical easterly jet (TEJ) at $200 \mathrm{hPa}$ around $10^{\circ} \mathrm{N}$, and the subtropical jet at $200 \mathrm{hPa}$ near $30^{\circ} \mathrm{N}$. The Saharan dust elongates the AEJ at $15^{\circ} \mathrm{N}$ and shifts the AEJ center northward (the bottom panels in Fig. 6; see also Fig. S8), since dust warms the middle atmosphere and 
(a) PRECC DUST 2005

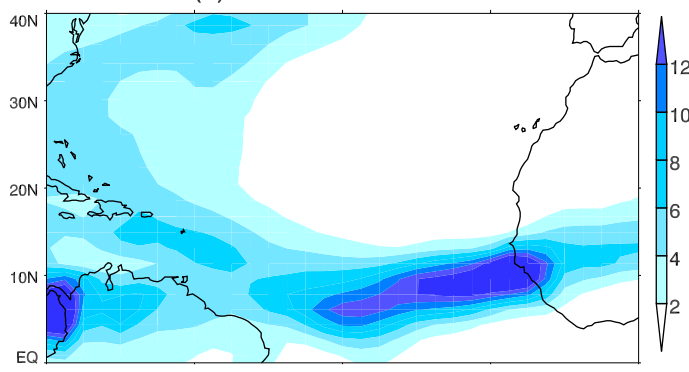

(c) PRECC DUST 2006

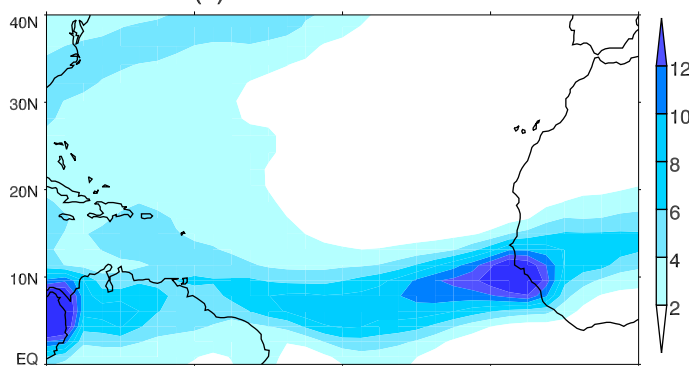

(e) PRECC D05-D06

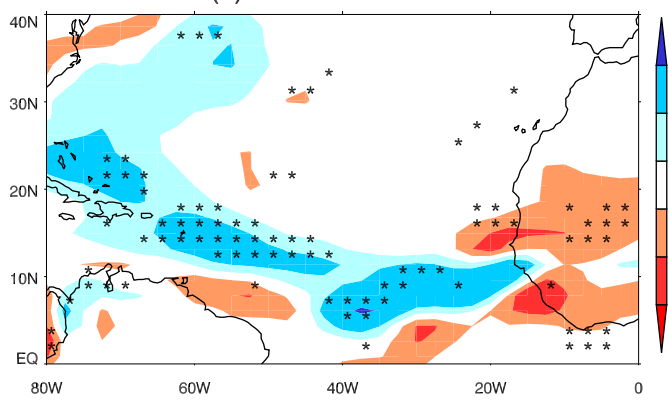

(b) PRECC D-ND 2005

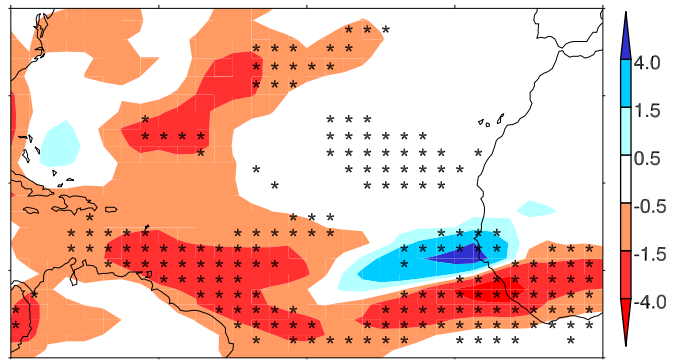

(d) PRECC D-ND 2006

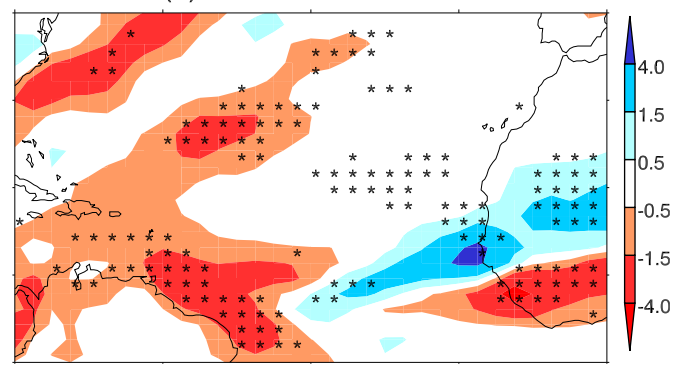

(f) PRECC ND05-ND06

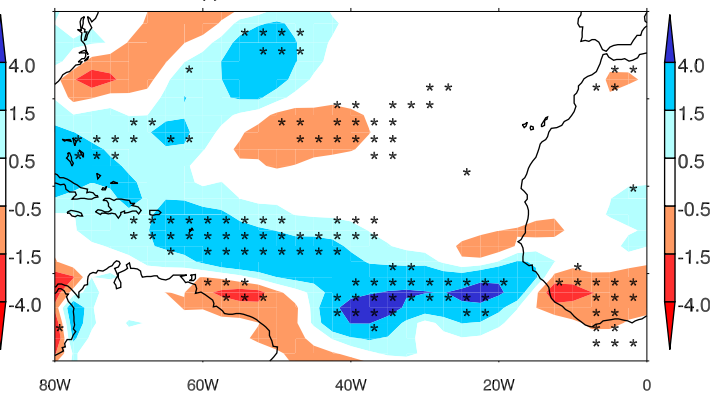

FIG. 5. As in Fig. 3, but for convective precipitation rate $\left(\mathrm{mm} \mathrm{day}^{-1}\right)$ in August 2005 and 2006.

increases the temperature contrast between land and ocean. The shift of the AEJ moves the lifting branch of the Hadley circulation northward (Fig. 6), thereby shifting the ITCZ northward. This finding agrees with the observed northward shift of the ITCZ by Wilcox et al. (2010). In addition, similar results on the movement of the Hadley cell by natural aerosols have been found in Randles et al. (2013) and Colarco et al. (2014).

Similarly, simulations of both resolutions show that the convective precipitation rate in 2005 is greater than that in 2006 over the western Caribbean region, with a dipole structure for the difference between the dust and nondust cases (Figs. S9c,f). However, there is less precipitation over the western Caribbean with the fineresolution simulation.

\section{c. Cloud fraction}

Figures $7 \mathrm{a}$ and $7 \mathrm{c}$ show the low cloud fraction labeled with $827-\mathrm{hPa}$ wind. The maximum low cloud fraction is near the West African coast and along $10^{\circ} \mathrm{N}$ in the Sahel region, corresponding to maritime stratus and shallow cumulus. Dust induces positive anomalies along the West African coast and along $10^{\circ} \mathrm{N}$ over the east Atlantic, and a negative anomaly to the north of $20^{\circ} \mathrm{N}$ over the mid-Atlantic (Figs. 7b,d). This is explained because dust induces a cyclonic thermal wind anomaly to the north of $20^{\circ} \mathrm{N}$ near the West African coast that decreases the offshore wind speed and leads to low clouds moving closer to the land. The largest decrease in temperature between the dust and nondust scenarios is located at $20^{\circ} \mathrm{N}$ over the West African continent, similar to the region with the maximum dust mixing ratio (Fig. S10). The temperature anomalies in Figs. S11c and S11d show that shortwave warming by dust dominates in the upper dust layer around $700 \mathrm{hPa}$. The warming in the atmosphere by absorbing dust intensifies the SHL and enhances the moist advection and West African monsoon, in agreement with Lau et al. (2009). Moreover, our 

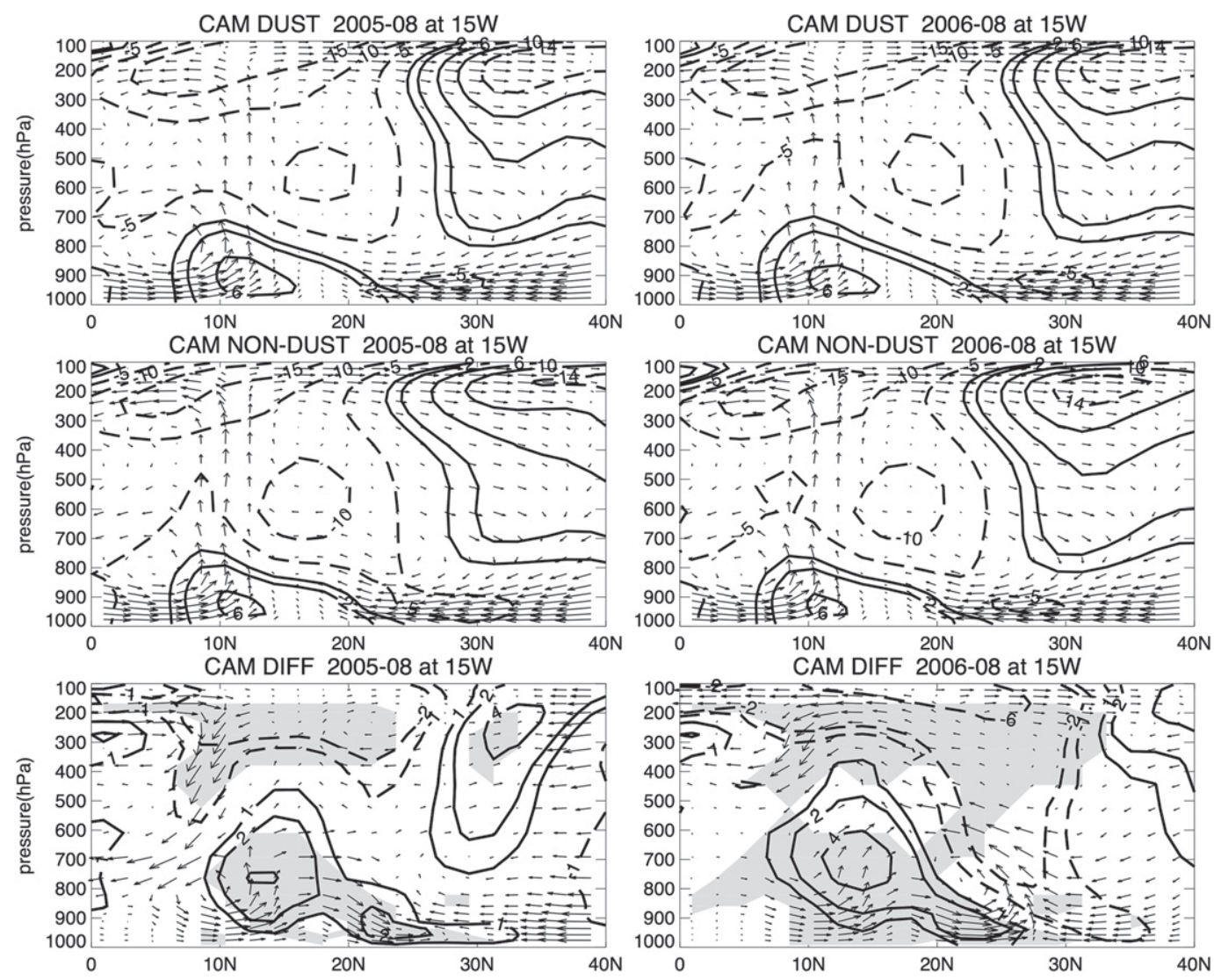

FIG. 6. Wind cross section at $15^{\circ} \mathrm{W}$ in August (left) 2005 and (right) 2006. The contours represent the zonal wind speed $\left(\mathrm{m} \mathrm{s}^{-1}\right)$; wind barbs are the summation of the meridional and vertical wind. Shown are the (top) dust and (middle) nondust scenarios, and (bottom) the differences between them. The dotted regions label the $95 \%$ significant level of the Student's $t$ test.

finding agrees with that of Wong et al. (2008), indicating that the dust-induced temperature anomaly (Figs. S10 and S11) perturbs the circulation at $700 \mathrm{hPa}$ by the thermal wind balance and modulates the cloud fraction and long-range transport of dust. Additionally, Figs. $7 \mathrm{~b}$ and $7 \mathrm{~d}$ show a consistent increase of a low cloud fraction over West Africa and an onshore low cloud fraction along the West African coast, indicating that dust effects on low clouds are independent of SST. In Figs. $7 \mathrm{e}$ and $7 \mathrm{f}$, there are insignificant differences in the low cloud fraction and $827-\mathrm{hPa}$ wind due to the SST variations.

Figure 8 shows the fraction of high clouds, including cirrus, cirrostratus, and deep convective clouds. Cirrus and cirrostratus trap the outgoing longwave radiation and thus warm the atmosphere. Deep convective clouds, on the other hands, reflect the shortwave radiation, trap the longwave radiation, and cool the surface. In Figs. 8a and 8c, the maximum high cloud fraction (greater than 0.8 ) is located along $10^{\circ} \mathrm{N}$ to the east of $35^{\circ} \mathrm{W}$, corresponding to the deep convective clouds in the ITCZ. Dust decreases (increases) the high cloud coverage in the west Atlantic (West Africa) (Figs. 8b,d). As mentioned previously, dust shifts and elongates the AEJ, changing the secondary circulation of the AEJ. The fraction of deep convective clouds decreases over the west Atlantic in the dust scenario due to the suppressed vertical motion but increases in the northsouth direction over West Africa due to the northward shift of the ITCZ. In addition, the enhancement of TEJ by dust (Fig. 6, bottom; see also Fig. S12) further inhibits the convective development in the jet region (Chen and van Loon 1987) over the west Atlantic. Moreover, the enhanced TEJ also contributes to the invigoration of the West African monsoon (Chen and van Loon 1987). The enhanced TEJ and elongated AEJ both decrease the high cloud fraction in the west Atlantic. In contrast, Colarco et al. (2014) found significant surface and tropospheric cooling at $500 \mathrm{hPa}$ due to dust, suggesting that the upper-level temperature anomaly enhances the AEJ through the thermal wind balance. The differences between our present work and that by Colarco et al. (2014) are likely caused by the variations of dust radiative properties employed in CAM5. 
(a) LOW CLD AND 827HPA WIND DUST 2005

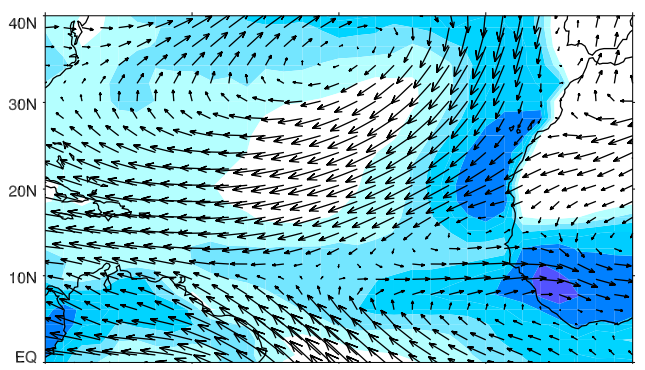

(c) LOW CLD AND 827HPA WIND DUST 2006

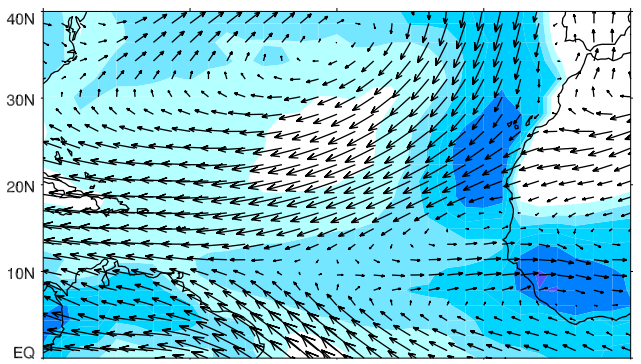

(e) LOW CLD AND 827HPA WIND D05-D06

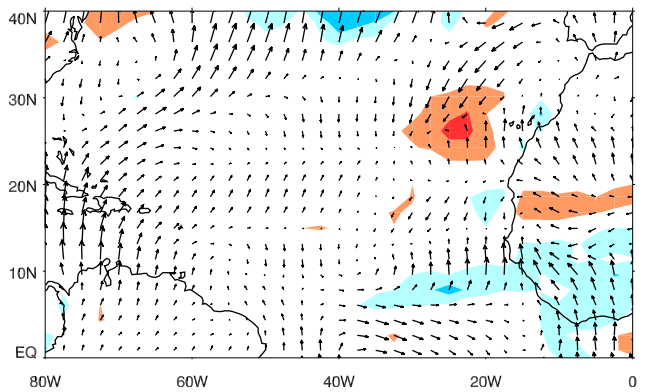

(b) LOW CLD AND 827HPA WIND D-ND 2005

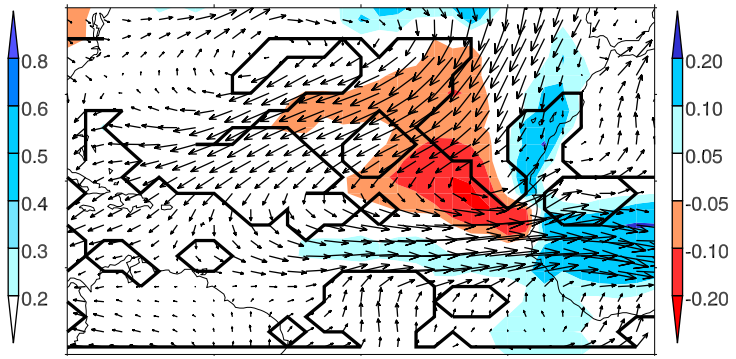

(d) LOW CLD AND 827HPA WIND D-ND 2006

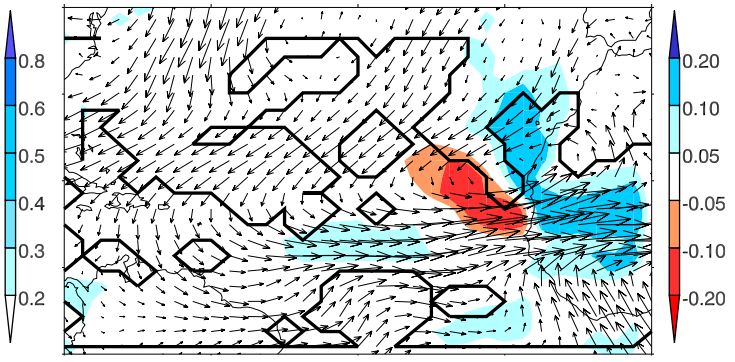

(f) LOW CLD AND 827HPA WIND ND05-ND06

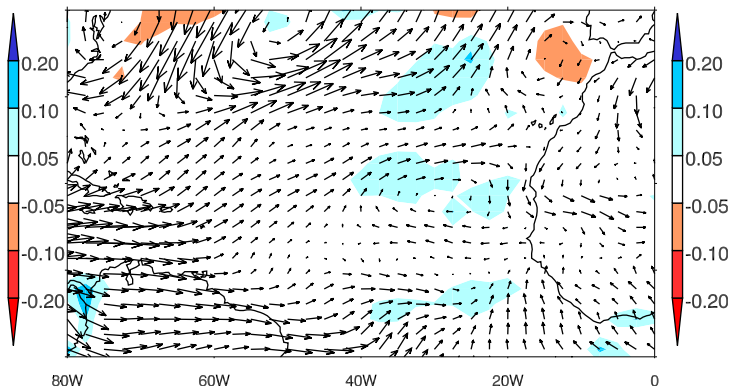

FIG. 7. As in Fig. 3, but for low cloud fraction labeled with 827-hPa wind in August 2005 and 2006.

The similar trends in Figs. $8 \mathrm{~b}$ and $8 \mathrm{~d}$ show that dust significantly decreases the high cloud fraction in the west Atlantic and increases the high cloud fraction along $15^{\circ} \mathrm{N}$ in West Africa, independent of SST. In Figs. 8e and 8f, there is a larger high cloud fraction over the eastern Caribbean along $10^{\circ} \mathrm{N}$ extending to the mid-Atlantic because of the warm SST in 2005, which enhances the AEJ (Figs. S8c,f) and the indirect circulation associated with the AEJ in 2005 with enhanced vertical motion in the eastern Caribbean. Overall, dust decreases the high cloud fraction whereas warmer SST increases high clouds in the eastern Caribbean. The high cloud anomaly caused by warm SST and dust likely counterbalance each other in this region.

\section{d. Radiation}

Figure 9 shows the clear-sky net solar flux at the top of the atmosphere (TOA). The lowest net flux $\left(300 \mathrm{~W} \mathrm{~m}^{-2}\right)$ is located over the Sahara, where there is the maximum dust extinction and surface reflection from the desert. Examination of the difference between the dust and nondust scenarios (Figs. 9b,d) shows that the lifted dust near the source region absorbs the surface-reflected solar radiation, decreasing the upward solar flux and increasing the net solar flux at TOA. On the other hand, the long-range transported dust over the ocean scatters solar radiation, decreasing the net solar flux at TOA. Hence, the clear-sky net radiative effect of dust at TOA depends on the surface reflectivity, exhibiting more absorption over the high albedo surface and more reflection on the low albedo surface. Our findings are consistent with those of Huang et al. (2014), Miller and Tegen (1998), and Mahowald et al. (2014). Moreover, the clear-sky radiative flux at TOA follows a similar trend under different SST conditions. In Fig. 9e, there is 
(a) HIGH CLOUD DUST 2005

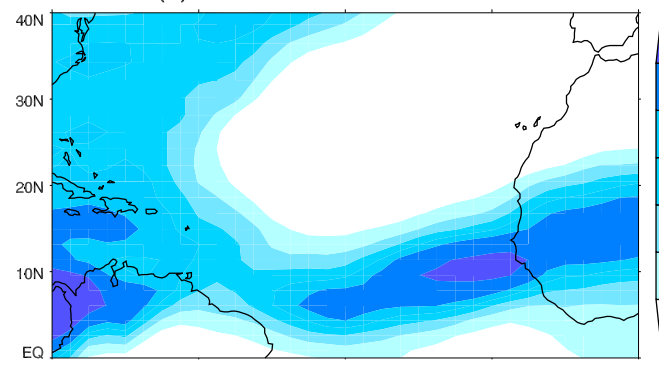

(c) HIGH CLOUD DUST 2006

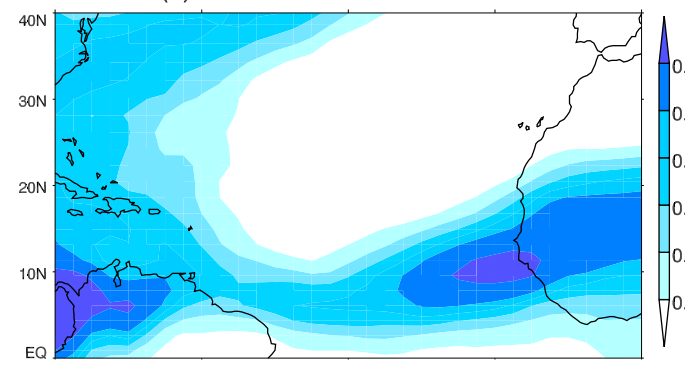

(e) HIGH CLOUD D05-D06

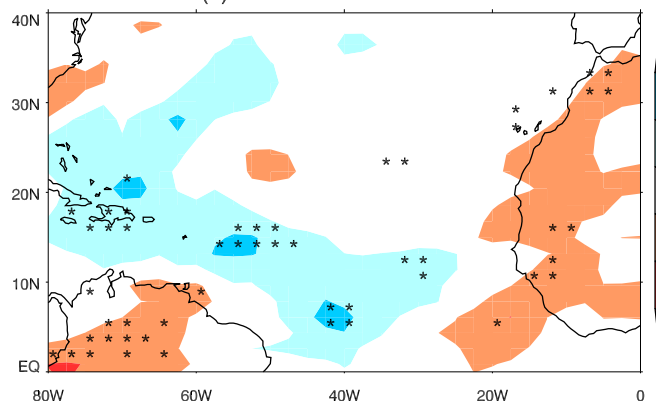

(b) HIGH CLOUD D-ND 2005

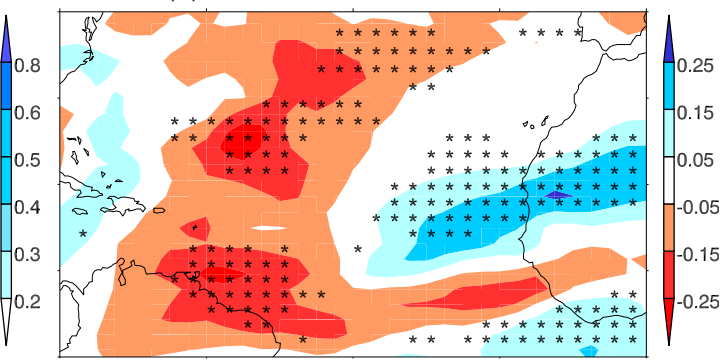

(d) HIGH CLOUD D-ND 2006

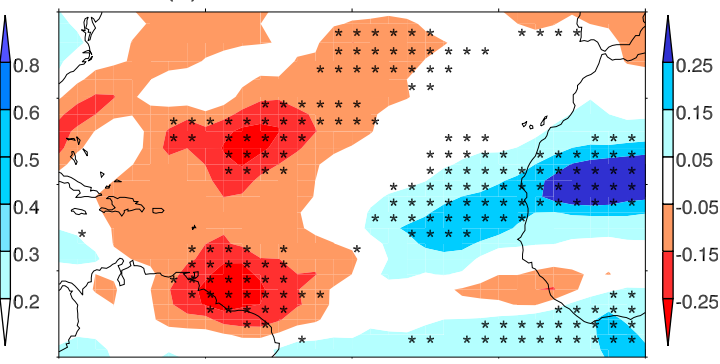

(f) HIGH CLOUD ND05-ND06

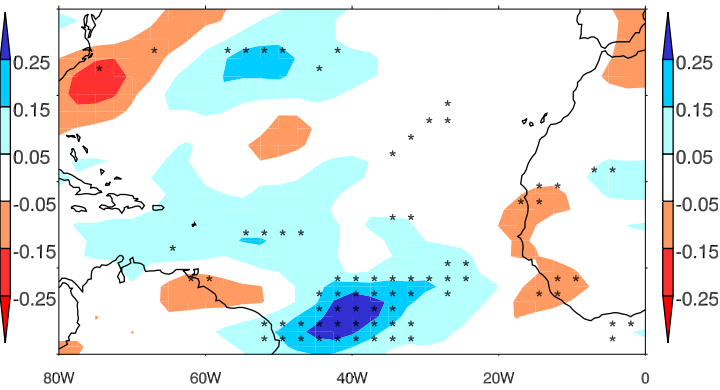

FIG. 8. As in Fig. 3, but for high cloud fraction in August 2005 and 2006.

an up to $4 \mathrm{~W} \mathrm{~m}^{-2}$ positive clear-sky net solar flux anomaly to the north of $15^{\circ} \mathrm{N}$ along the coast of West African, due to the decrease (increase) of dust emissions from the Sahara over the area south (north) of $20^{\circ} \mathrm{N}$ in 2006 (Fig. S4e). A decreased flux of $4 \mathrm{~W} \mathrm{~m}^{-2}$ to the south of $15^{\circ} \mathrm{N}$ over the east Atlantic (Fig. 9e) is caused by the high aerosol loading and scattering in this region in 2005 (Fig. S4f). The increased clear-sky radiative flux in the eastern Caribbean is possibly due to the lower aerosol loading (Fig. S4f) in 2005, which decreases the absorption by aerosols and decreases the upward radiative flux. Overall, the dust effects are counterbalanced by the positive clear-sky radiative flux anomalies induced by warm SST over the eastern Caribbean. Moreover, the dust radiative effect decreases the clear-sky net solar flux at TOA and is more pronounced than the SST impact.

Figure 10 shows the surface net radiative flux under the all-sky condition, which is calculated by the sum of net solar radiation and the net longwave radiation. The positive net radiative forcing indicates a net radiative heating in the column. The minimum net radiative flux $\left(530 \mathrm{~W} \mathrm{~m}^{-2}\right)$ is associated with deep convective clouds in the ITCZ, since the clouds reflect the solar radiation and trap the longwave radiation. Dust reduces the net radiative flux at surface by up to $30 \mathrm{~W} \mathrm{~m}^{-2}$ to the north of $15^{\circ} \mathrm{N}$ along the coast of West Africa and Sahel as well as the eastern tropical Atlantic (Figs. 10b,d) by expanding the deep convective cloud fraction along the northsouth direction. An increase in the high cloud fraction by dust increases the upward radiative flux at the TOA and decreases the net radiation at surface. Dust decreases the solar flux at the surface by $4 \mathrm{~W} \mathrm{~m}^{-2}$ along $10^{\circ} \mathrm{N}$ to the east of $40^{\circ} \mathrm{W}$ (Fig. 9e). In addition, clouds decrease the net radiative flux up to $30 \mathrm{~W} \mathrm{~m}^{-2}$ in this region. Figures 10e and 10f show that the warm SST in 2005 decreases the surface net radiative flux by about $30 \mathrm{~W} \mathrm{~m}^{-2}$ along $10^{\circ} \mathrm{N}$ over the east Atlantic, due to the more intense convective precipitation rate along $10^{\circ} \mathrm{N}$ in 
(a) CS RAD at TOA $\left(\mathrm{W} \mathrm{m}^{-2}\right)$ DUST 2005

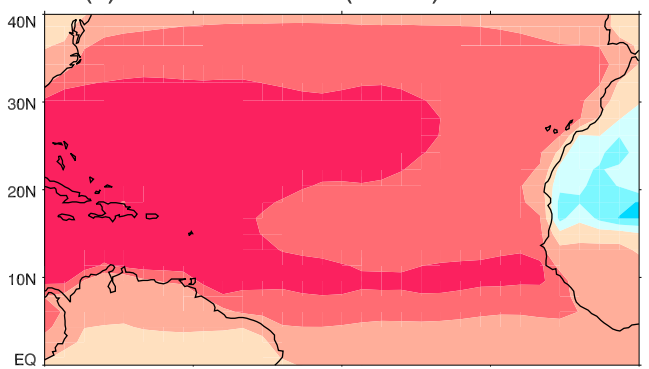

(c) CS RAD at TOA ( $\left.\mathrm{W} \mathrm{m}^{-2}\right)$ DUST 2006

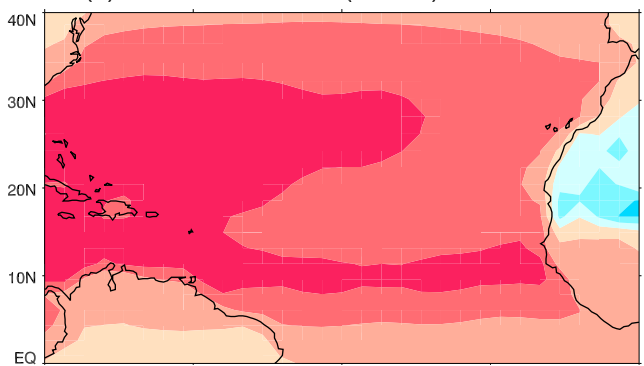

(e) CS RAD at TOA (W m $\left.{ }^{-2}\right)$ D05-D06

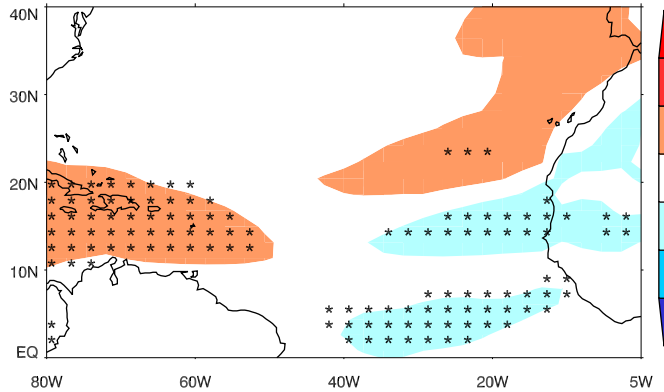

(b) CS RAD at TOA $\left(\mathrm{W} \mathrm{m}^{-2}\right)$ D05-ND05

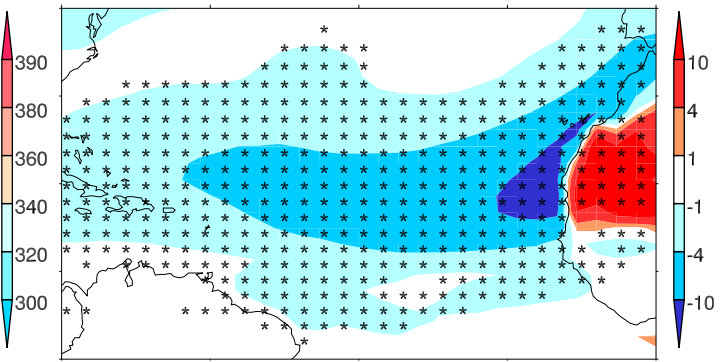

(d) CS RAD at TOA (W m $\left.{ }^{-2}\right)$ D06-ND06

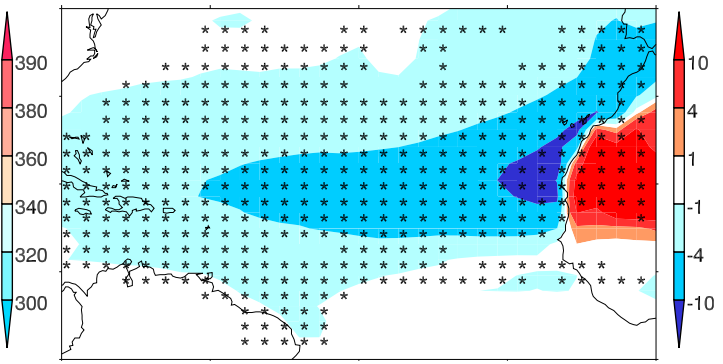

(f) CS RAD at TOA ( $\left.\mathrm{W} \mathrm{m}^{-2}\right)$ ND05-ND06

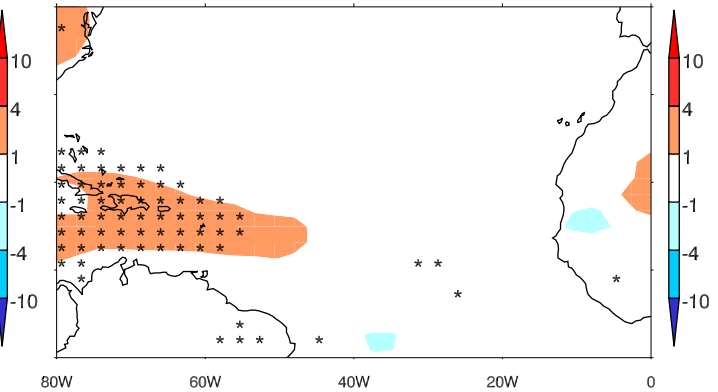

FIG. 9. As in Fig. 3, but for clear-sky solar flux $\left(\mathrm{W} \mathrm{m}^{-2}\right)$ at TOA in August 2005 and 2006.

2005. Qualitatively, there is a larger (smaller) area with negative (positive) radiative flux induced by the dust in 2006 (Fig. 10d) compared with those in 2005 (Fig. 10b). These findings agree with Lau and Kim $(2007 \mathrm{a}, \mathrm{b})$ on more dust loading in 2006 that decreases the surface solar radiation. Dust, together with the warm SST, decreases the surface net radiative flux along $10^{\circ} \mathrm{N}$ over the east Atlantic. Moreover, dust shows similar impacts on the surface net radiative flux between 2005 and 2006, indicating its independence on SST.

A previous study by Zhao et al. (2013) investigated the sensitivities of the net radiative flux on the variations of dust visible imaginary refractive index in CAM5.1 and found a high sensitivity of the net radiation at TOA over the dust source region to the variation of dust visible imaginary refractive index. Overall, the absorption and scattering of shortwave radiation by dust modify the net radiation at surface by changing atmospheric moisture and cloud distributions, significantly reducing the surface net radiative flux over the east Atlantic region.

\section{e. Large-scale environments relevant to TC activity}

In addition to the vital roles in the regional hydrological cycle and radiative budget, dust also influences the tropical cyclogenesis by modifying the dynamics and thermodynamics conditions over the GNR and ITR regions of the Atlantic basin. Several key variables, including low-level vorticity, midlevel vertical wind shear, moisture, entropy deficit (Emanuel and Nolan 2004), PI (Bister and Emanuel 2002), and VI (Tang and Emanuel 2012) are examined. The low-level vorticity induces rotation to the convective systems and increases the air spirals into the storm center. A positive vorticity represents the cyclonic motion, which is favorable for the TC genesis and development. The vertical component of the relative vorticity is calculated using 
(a) SRFRAD ( $\left.\mathrm{W} \mathrm{m}^{-2}\right)$ DUST 2005

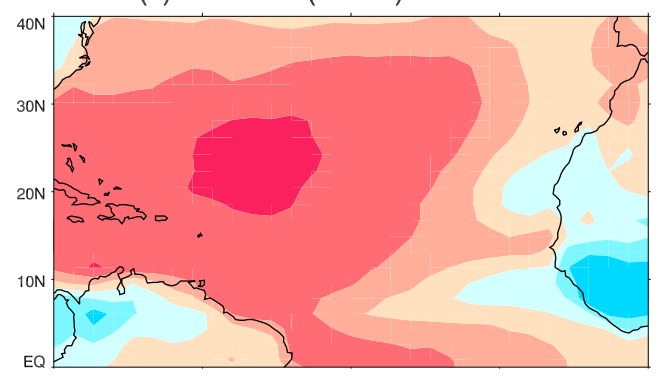

(c) SRFRAD ( $\left.\mathrm{W} \mathrm{m}^{-2}\right)$ DUST 2006

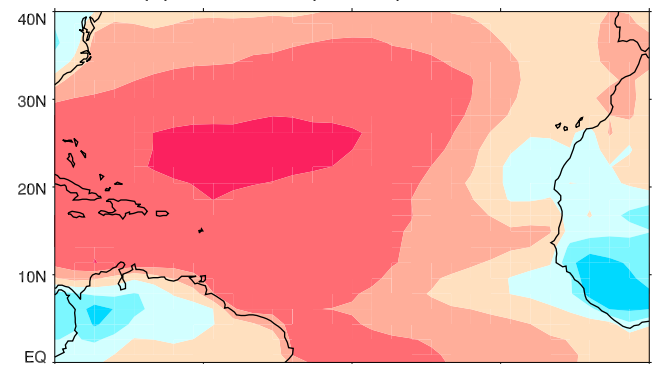

(e) SRFRAD $\left(\mathrm{W} \mathrm{m}^{-2}\right)$ D05-D06

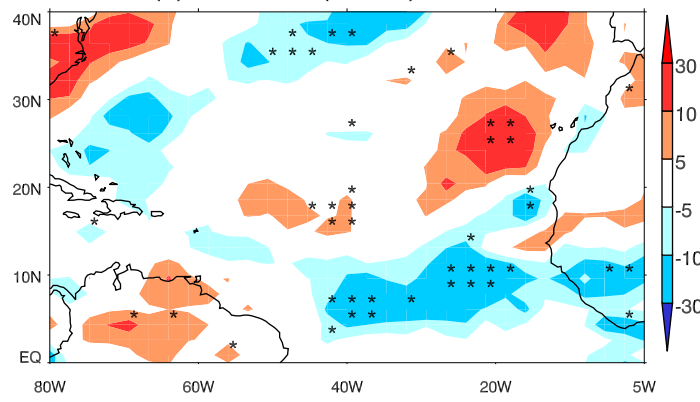

(b) SRFRAD ( $\mathrm{W} \mathrm{m}^{-2}$ ) D05-ND05

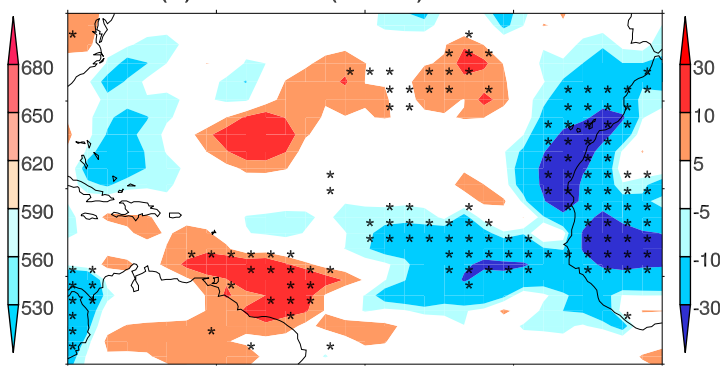

(d) SRFRAD ( $\left.\mathrm{W} \mathrm{m}^{-2}\right)$ D06-ND06

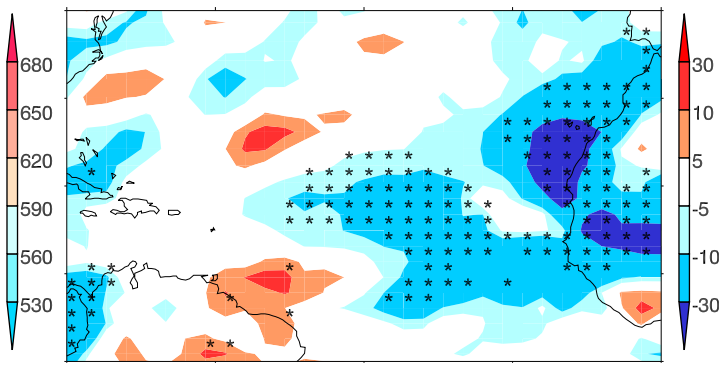

(f) SRFRAD ( $\left.\mathrm{W} \mathrm{m}^{-2}\right)$ ND05-ND06



$60 \mathrm{~W}$

FIG. 10. As in Fig. 3, but for surface net radiative flux $\left(\mathrm{W} \mathrm{m}^{-2}\right)$ in August 2005 and 2006.

$$
\zeta=\frac{\partial v}{\partial x}-\frac{\partial u}{\partial y}=\frac{v_{i+1, j}-v_{i, j}}{\Delta x}-\frac{u_{i, j+1}-u_{i, j}}{\Delta y},
$$

where $i$ and $j$ represent the grid index, and $\Delta x$ and $\Delta y$ are the grid space in the $x$ and $y$ direction, respectively. The 925-hPa relative vorticity is shown in Fig. 11. The positive vorticity region is located to the north of the ITCZ and adjacent to the SHL. The negative vorticity is located to the south of the ITCZ (Figs. 11a, c). The positive vorticity anomaly around the western Sahara in Figs. $11 \mathrm{~b}$ and $11 \mathrm{~d}$ further supports our previous point that dust enhances the SHL. The decreasing vorticity in the GNR by dust likely suppresses the development of TCs (Gray 1998). The enhancement of the West African monsoon by dust increases the positive vorticity north of the ITCZ and decreases the negative vorticity to the south of the ITCZ. Hence, the increase in the positive vorticity by dust likely increases the low-level convergence and favors the development of TCs (Zehr 1992) to the north of $10^{\circ} \mathrm{N}$, especially in the ITR. Figures $11 \mathrm{e}$ and $11 \mathrm{f}$ show an insignificant variation of low-level vorticity by SST. The combined effects of dust and SST in this region are not clear, seeing the noisy responses of low-level vorticity to dust and insignificant variations by SST. Simulations using the finer resolution show similar patterns in the low-level vorticity, although the decrease (increase) of the low-level vorticity in the GNR (ITR) region is less pronounced compared to the coarse-resolution simulations.

The vertical wind shear is calculated from the absolute differences of wind vectors between 850 and $200 \mathrm{hPa}$. A relatively weak vertical wind shear $\left(10-15 \mathrm{~m} \mathrm{~s}^{-1}\right)$ favors the vertical development of tropical vortices (Bracken and Bosart 2000). Figure 12 shows that the maximum wind shear $\left(20 \mathrm{~m} \mathrm{~s}^{-1}\right)$ is distributed along $10^{\circ} \mathrm{N}$ over the 
(a) VOR $925 \mathrm{hPa}$ DUST 2005

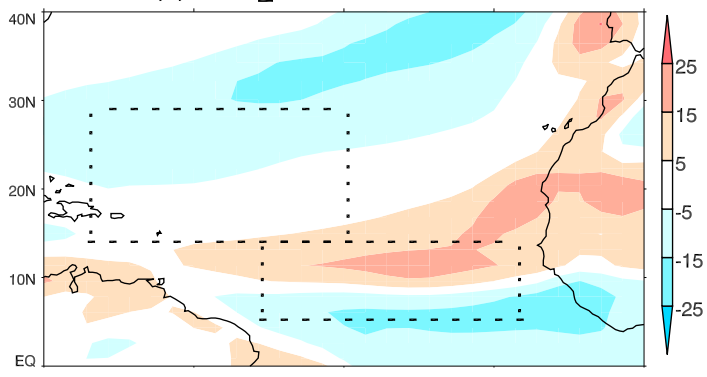

(c) VOR_925hPa DUST 2006

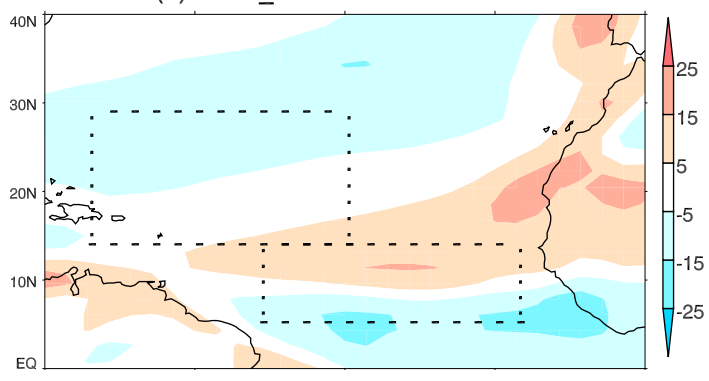

(e) VOR $925 \mathrm{hPa}$ D05-D06

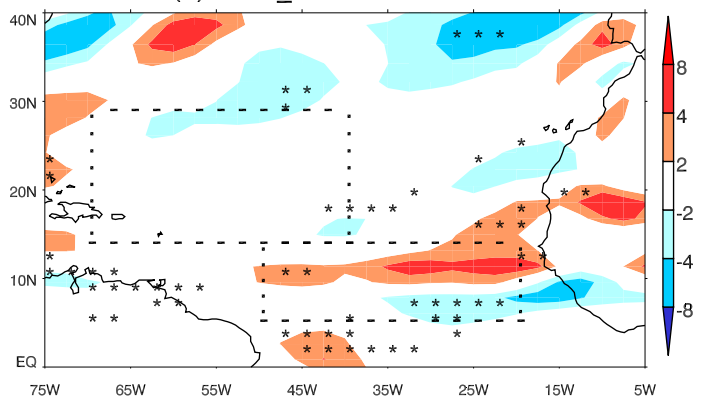

(b) VOR $925 \mathrm{hPa}$ D05-ND05

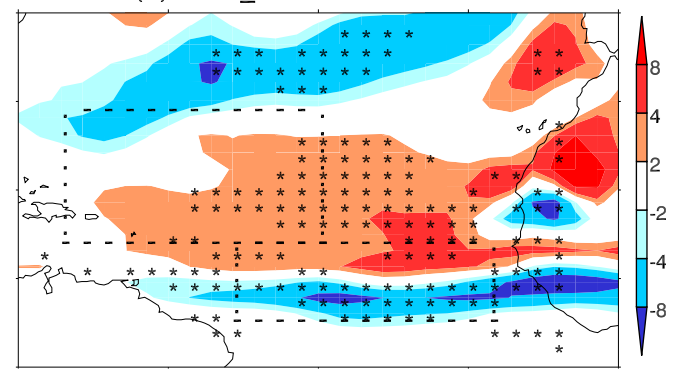

(d) VOR_925hPa D06-ND06

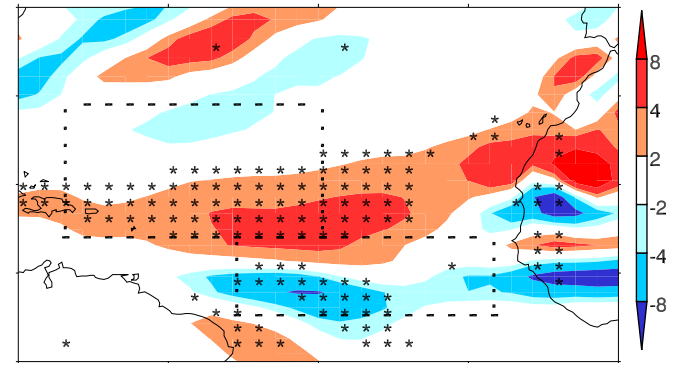

(f) VOR_925hPa ND05-ND06

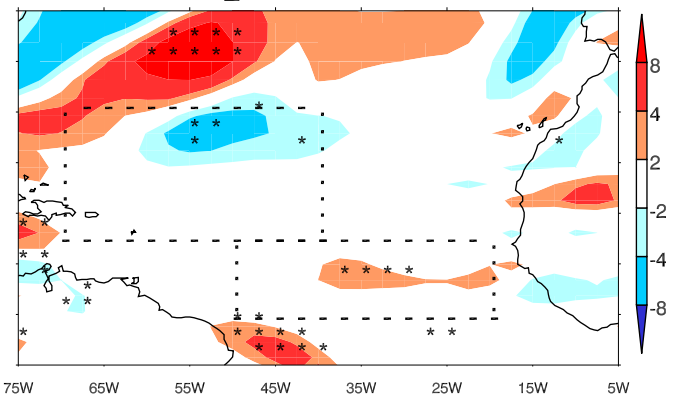

FIG. 11. As in Fig. 3, but for low-level vorticity at $925 \mathrm{hPa}\left(10^{-6} \mathrm{~s}^{-1}\right)$ in August 2005 and 2006.

east Atlantic and West Africa. In the dust scenario, the maximum wind shear increases more than $7 \mathrm{~m} \mathrm{~s}^{-1}$ along $10^{\circ} \mathrm{N}$ (Figs. $12 \mathrm{~b}, \mathrm{~d}$ ), due to the enhanced TEJ at $200 \mathrm{hPa}$ and West African monsoon around $850 \mathrm{hPa}$ by dust. This increase in wind shear further suppresses the development of TCs in the GNR. The minimum wind shear region, located near the central tropical Atlantic, represents the favorable condition for generation and invigoration of TCs. The vertical wind shear difference in Figs. $12 \mathrm{~b}$ and $12 \mathrm{~d}$ indicates that dust significantly increases the vertical wind shear by up to $7 \mathrm{~m} \mathrm{~s}^{-1}$ in the GNR but decreases the wind shear (from -7 to $-3 \mathrm{~m} \mathrm{~s}^{-1}$ ) in the ITR, corresponding to unfavorable and favorable TC genesis in the GNR and ITR, respectively. In Figs. 12e and 12f, the warm SST in 2005 induces a negative wind shear anomaly in the ITR, consistent with an active hurricane season in 2005. The effects of dust and SST decrease the wind shear in the ITR, providing favorable conditions for TC activities. On the other hand, the wind shear condition in the GNR is insignificantly varied by SST and dominated by the dustinduced positive wind shear anomaly, which suppresses the TC development in this region.

In addition, the midlevel moisture represents the latent energy supplies to TC genesis and intensification from the thermodynamics perspective and is represented by the specific humidity at $827 \mathrm{hPa}$ (Fig. 13). The maximum specific humidity is distributed along the ITCZ, whereas the minimum specific humidity is located around $30^{\circ} \mathrm{N}$ in the northeastern Atlantic and North Africa. In Figs. 13b and 13d, dust increases the water vapor content along $20^{\circ} \mathrm{N}$, likely explained by the enhanced moist advection to West Africa due to the enhancement of SHL. The increased moisture content potentially increases the latent energy resource for the development of TCs in the GNR and ITR regions. In 
(a) WIND SHEAR 200hPa-850hPa DUST 2005

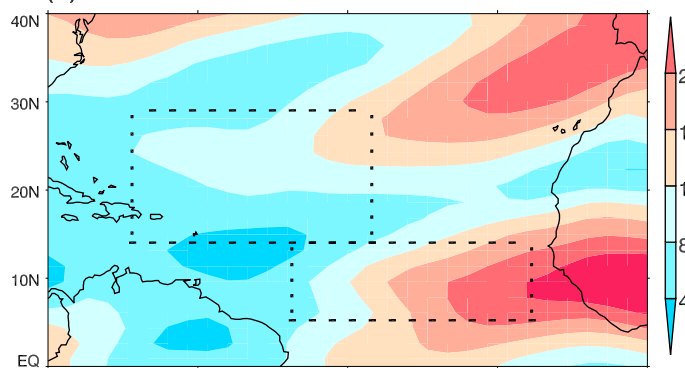

(c) WIND SHEAR 200hPa-850hPa DUST 2006

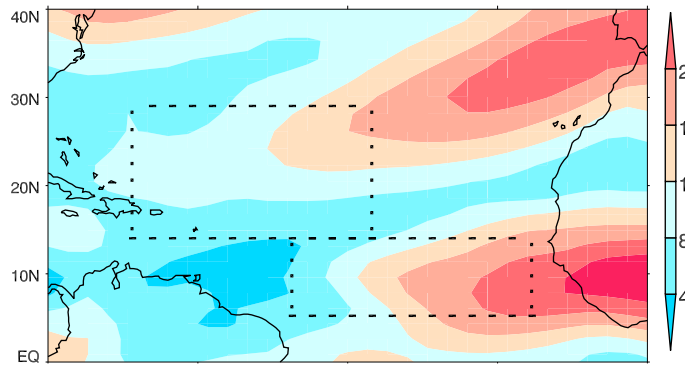

(e) WIND SHEAR 200hPa-850hPa D05-D06

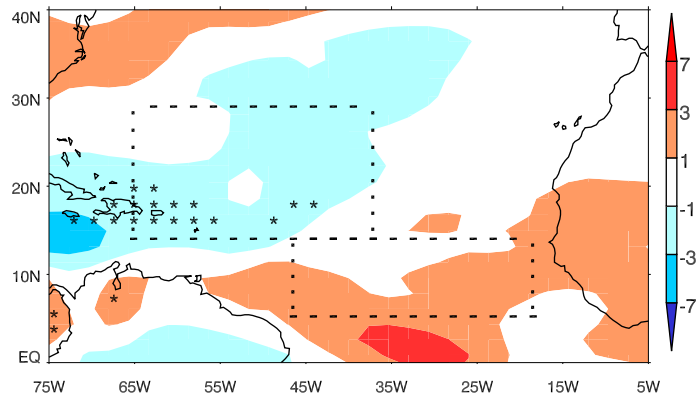

FIG. 12. As in Fig. 3, but for vertical wind shear $\left(\mathrm{m} \mathrm{s}^{-1}\right)$ between 850 and $200 \mathrm{hPa}$ in August 2005 and 2006. (b) WIND SHEAR 200hPa-850hPa D05-ND05

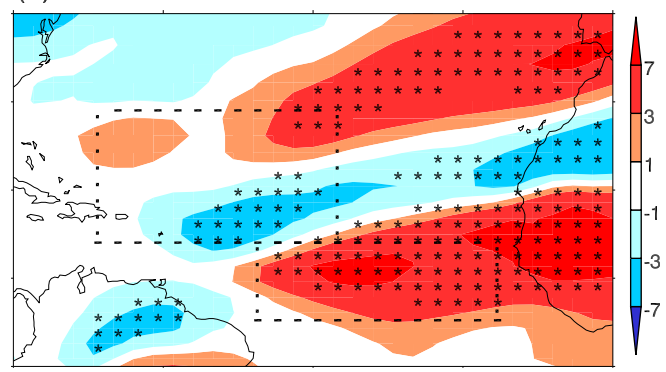

(d) WIND SHEAR 200hPa-850hPa D06-ND06

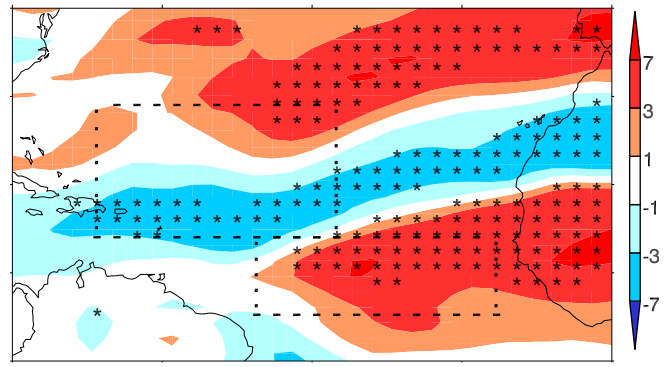

(f) WIND SHEAR 200hPa-850hPa ND05-ND06

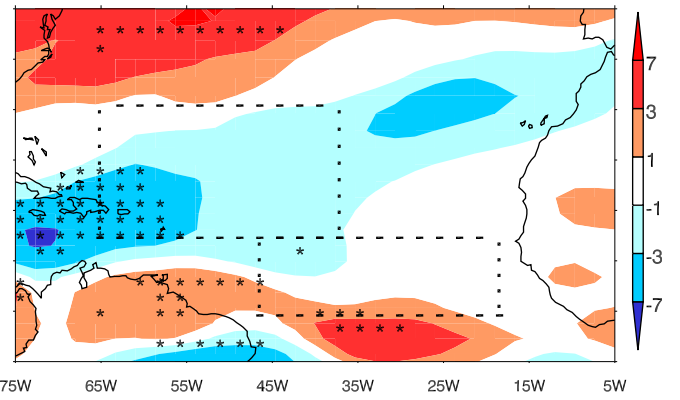

Figs. $13 \mathrm{e}$ and $13 \mathrm{f}$, the specific humidity in 2005 is higher than that in 2006 in the GNR to the north of $15^{\circ} \mathrm{N}$ over the west Atlantic, due to the relatively warm SST. Dust and warm SST both induce positive specific humidity anomalies in this region. On the other hand, the warm SST decreases the specific humidity on the north of $20^{\circ} \mathrm{N}$ over the east Atlantic, offsetting the dust-induced positive anomaly in this region.

The entropy deficit $\chi_{m}$ is defined as the ratio of the low-level energy supply to the midlevel moisture (Tang and Emanuel 2012) by

$$
\chi_{m}=\frac{S_{m}^{*}-S_{m}}{S_{\mathrm{SST}}^{*}-S_{b}}
$$

where $S_{m}$ is the environmental entropy, and $S_{m}^{*}$ is the saturation entropy in the middle atmosphere $(600 \mathrm{hPa})$; also, $S_{\mathrm{SST}}^{*}$ is the saturation entropy at SST, and $S_{b}$ is the entropy of the boundary layer. The denominator is the air-sea entropy difference, which represents the entropy gradient to the convective system. The numerator illustrates the midlevel moisture by comparing the saturated and environmental entropies. A small entropy deficit means either a large air-sea entropy difference (i.e., sufficient energy support) or a moist middle atmosphere that favors the TC genesis. Figures $14 \mathrm{a}$ and $14 \mathrm{c}$ show that the minimum entropy deficit is collocated along the ITCZ, where there is a significant amount of moisture in the middle troposphere due to the deep convection. The difference between the dust and nondust scenarios shows that dust decreases the entropy deficit along $10^{\circ} \mathrm{N}$ by increasing the liquid water content in the midtroposphere. Moreover, the entropy deficit increases significantly to the north of $10^{\circ} \mathrm{N}$ along the West African coast, corresponding to a decrease of moisture and entropy 
(a) SH $\left(\mathrm{g} \mathrm{kg}^{-1}\right)$ DUST 2005

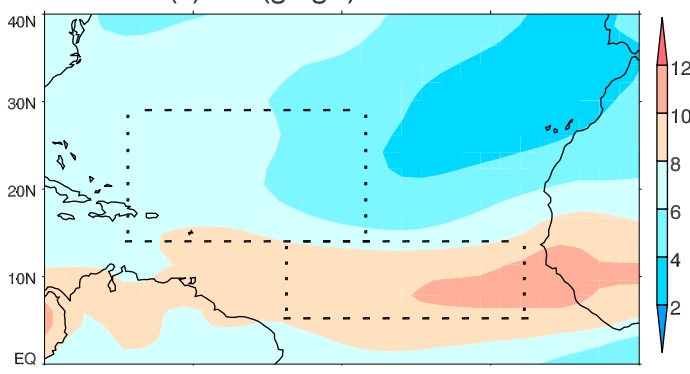

(c) SH $\left(\mathrm{g} \mathrm{kg}^{-1}\right)$ DUST 2006

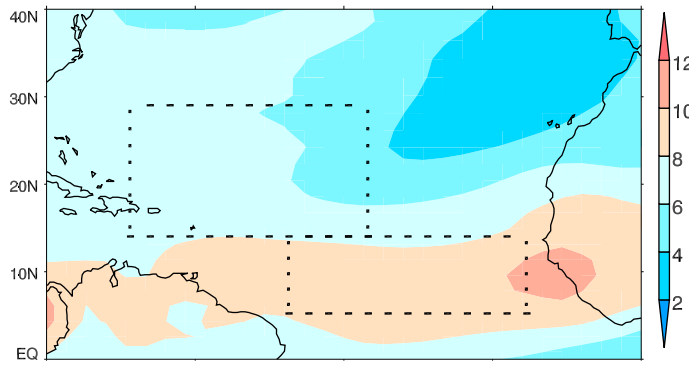

(e) $\mathrm{SH}\left(\mathrm{g} \mathrm{kg}^{-1}\right)$ D05-D06

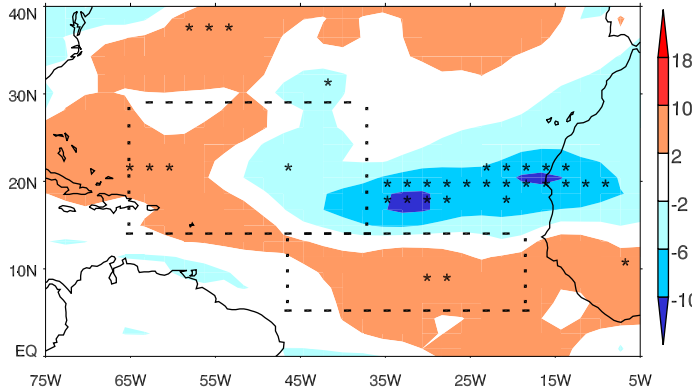

(b) $\mathrm{SH}\left(10^{-1} \mathrm{~g} \mathrm{~kg}^{-1}\right)$ D05-ND05

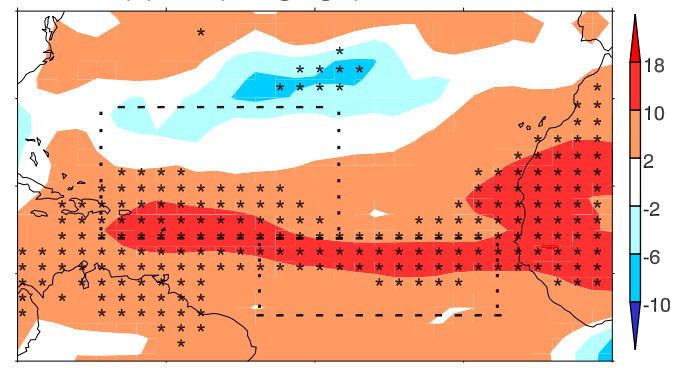

(d) $\mathrm{SH}\left(10^{-1} \mathrm{~g} \mathrm{~kg}^{-1}\right)$ D06-ND06

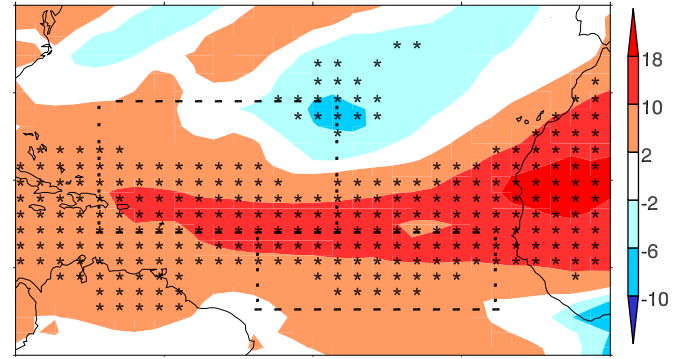

(f) $\mathrm{SH}\left(\mathrm{g} \mathrm{kg}^{-1}\right)$ ND05-ND06

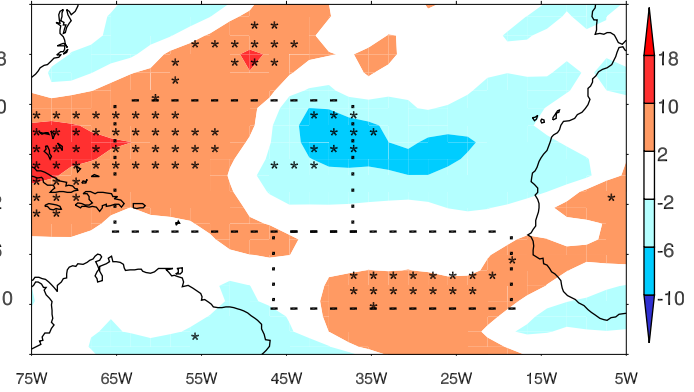

FIG. 13. As in Fig. 3, but for specific humidity $\left(\mathrm{g} \mathrm{kg}^{-1}\right)$ at $827 \mathrm{hPa}$ in August 2005 and 2006. The units in (b) and (d) are $10^{-1} \mathrm{~g} \mathrm{~kg}^{-1}$.

in the planetary boundary layer by dust. Hence, the entropy deficit is decreased in the GNR, which favors the genesis of TCs. In Figs. 14e and 14f, the entropy deficit is lower in both the ITR and GNR in 2005 than in 2006, consistent with an inactive hurricane season in 2006. Both dust and warm SST induce a negative entropy deficit in the GNR, providing a favorable condition for TC development. On the other hand, the dust and warm SST show a similar magnitude of entropy deficit in the west Atlantic and Caribbean regions and likely exhibit an offset effect. Interestingly, there is a significant decrease in the entropy deficit over the west Atlantic in 2005 compared to 2006 (Fig. 14f), suggesting the likelihood of westward TC movement toward the Gulf of Mexico in 2005.

The PI, which represents the possibly maximum intensity of the TC, is calculated according to Bister and Emanuel (2002) under pseudoadiabatic assumptions by

$$
\operatorname{Vmax}^{2}=\frac{T_{s}}{T_{0}} \frac{C_{k}}{C_{D}}\left(\mathrm{CAPE}^{*}-\mathrm{CAPE}\right)_{m},
$$

where $T_{s}$ is the SST, and $T_{0}$ is the mean outflow temperature; $C_{k}$ is the exchange coefficient for enthalpy, and $C_{D}$ is the drag coefficient. CAPE is the convective available potential energy of air lifted from the boundary layer in reference to the environmental sounding, where CAPE* is that lifted from the saturation at sea level. Both values are evaluated from the radius of the maximum wind speed. The maximum velocity ( $\mathrm{Vmax}$ ) is employed for the representation of the PI. In Figs. 15a and $15 \mathrm{c}$, the relatively high PI values extend along the ITCZ toward the west Atlantic and reach a maximum $\left(85 \mathrm{~m} \mathrm{~s}^{-1}\right)$ in the Caribbean region. Comparing 2005 and 2006 (Figs. 15e,f), there is a higher maximum velocity over the ITR and Caribbean in 2005, corresponding to a favorable condition for TC activities. On the other hand, 
(a) ENTROPY DEFICIT DUST 2005

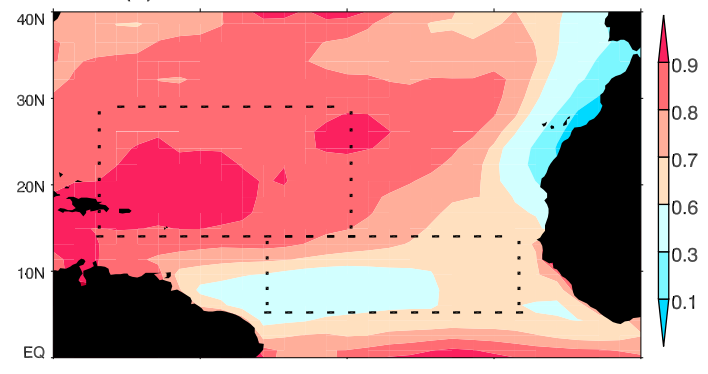

(c) ENTROPY DEFICIT DUST 2006

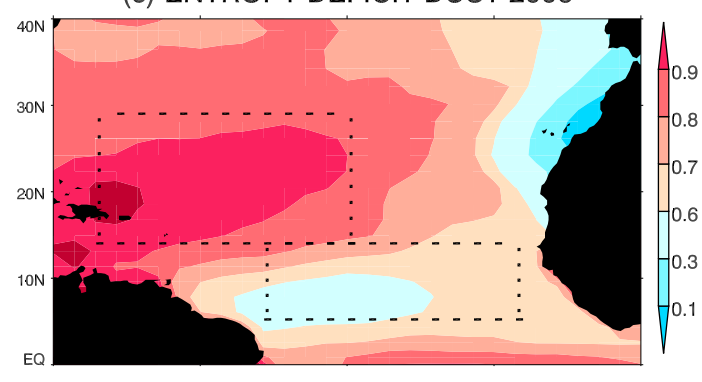

(e) ENTROPY DEFICIT D05-D06

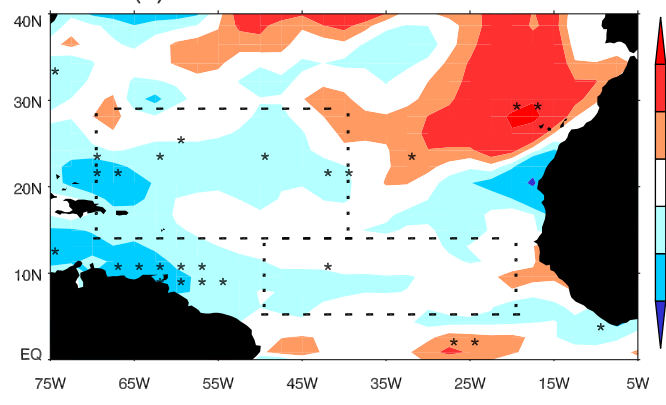

(b) ENTROPY DEFICIT D05-ND05

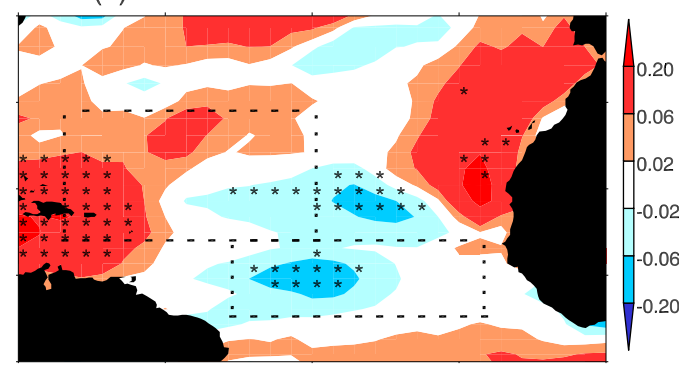

(d) ENTROPY DEFICIT D06-ND06



(f) ENTROPY DEFICIT ND05-ND06

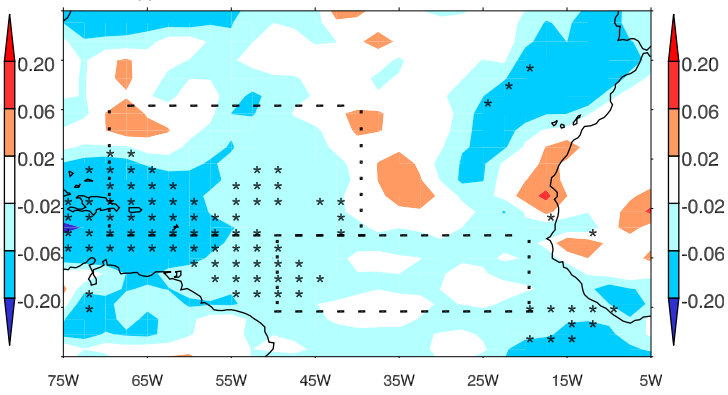

FIG. 14. As in Fig. 3, but for entropy deficit $\chi_{m}$ in August 2005 and 2006.

dust plays an opposite role in determining PI (Figs. 15b,d) by decreasing the PI value up to $15 \mathrm{~m} \mathrm{~s}^{-1}$ near the dust source region in the east Atlantic and $2-4 \mathrm{~m} \mathrm{~s}^{-1}$ in both the ITR and GNR. Overall, dust decreases the PI and results in unfavorable conditions for TC activity especially near the dust source region, whereas the warmer SST has a major impact over the Caribbean region and increases the PI in that region, providing a favorable condition for the TC activities.

$$
\mathrm{VI}=\frac{\text { wind shear } \times \chi_{m}}{\operatorname{Vmax}}
$$

The VI is defined as the ratio of the product of wind shear with entropy deficit to PI (Tang and Emanuel 2012) in Eq. (5), which combines the dynamics and thermodynamics components that determine the favorability of TC activities. A low to moderate vertical wind shear, a high PI, and a low entropy deficit favor the
TC development, corresponding to a low VI value. Figures 16a and $16 \mathrm{c}$ show a VI value of less than 0.1 over the west Atlantic, corresponding to favorable TC activities in this region. In Figs. 16b and 16d, dust increases the VI in the GNR but decreases VI in the ITR, suppressing and enhancing TC activities over the GNR and ITR, respectively. In Figs. 16e and 16f, the VI value in the ITR is lower by 0.1 in 2005 than in 2006, representing a relatively favorable condition for TCs in 2005 due to the warm SST. Overall, the dust effects and warmer SST both favor TC activities in the ITR, while the dust effects dominate in the GNR and suppress TC activities, since the warmer SST does not show a significant impact over this region. The vertical wind shear represents the dominant term for the VI in both the ITR and GNR.

Overall, Saharan dust significantly impacts the TC genesis by modulating the thermodynamic and dynamic conditions of the environment. In the GNR, the 
(a) POTENTIAL INTENSITY DUST 2005

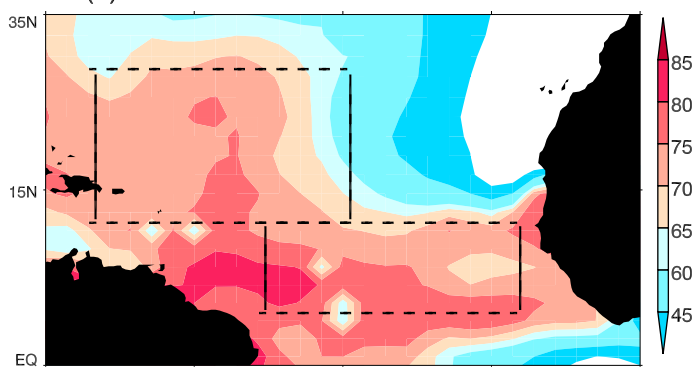

(c) POTENTIAL INTENSITY DUST 2006

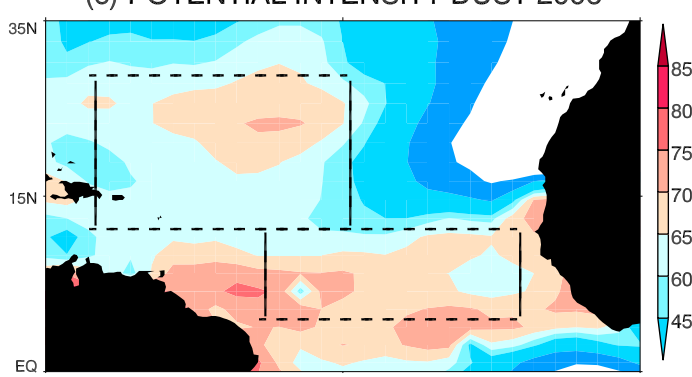

(e) POTENTIAL INTENSITY D05-D06



(b) POTENTIAL INTENSITY D05-ND05

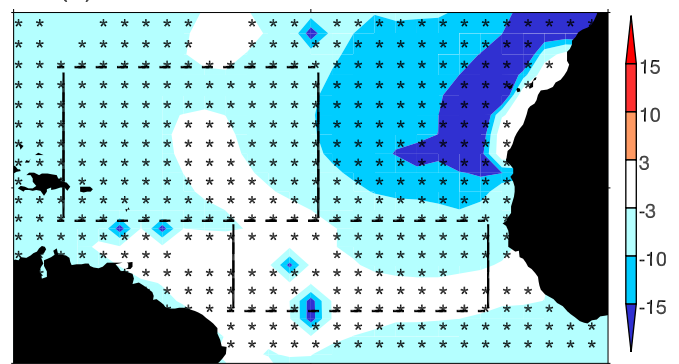

(d) POTENTIAL INTENSITY D06-ND06

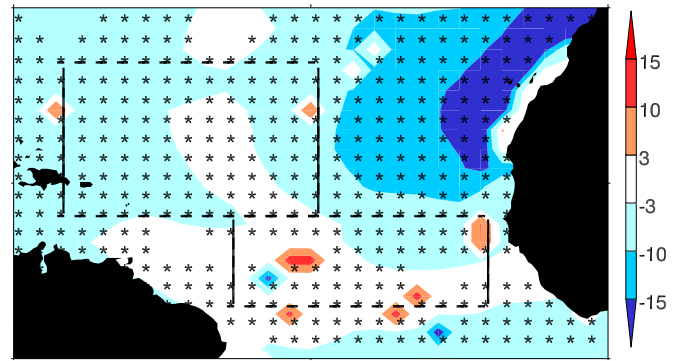

(f) POTENTIAL INTENSITY ND05-ND06

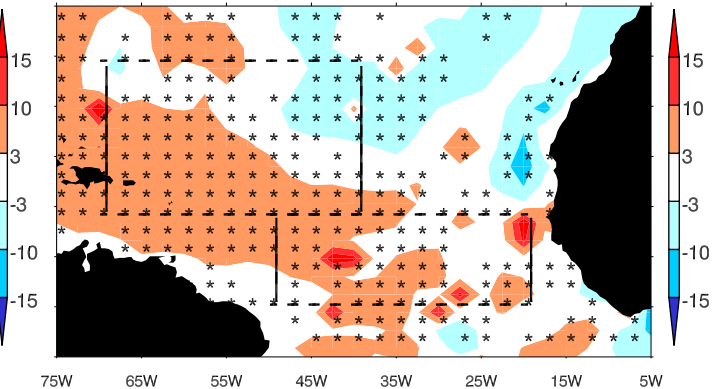

FIG. 15. As in Fig. 3, but for potential intensity $\left(\mathrm{m} \mathrm{s}^{-1}\right)$ in August 2005 and 2006.

increased midlevel moisture and decreased entropy deficit by dust increase the favorability for TC genesis, but the increased vertical wind shear, decreased lowlevel vorticity, and decreased PI by dust suppress the TC genesis. Moreover, in the ITR, dust increases the TC favorability by decreasing the vertical wind shear and increasing the midlevel moisture, but decreases the TC possibility by decreasing PI in maximum velocity. An examination of VI reveals that dust increases and decreases the TC favorability in the ITR and GNR, respectively. In general, there is a favorable TC condition in ITR in 2005 with an increasing midlevel moisture and PI in maximum velocity, and decreasing vertical wind shear and entropy deficit, due to the relatively warm SST. Both dust and warm SST favor the TC activities in the ITR, but dust likely suppresses TC activities in the GNR. Additionally, there are similar spatial distributions of the low-level vorticity, vertical wind shear, specific humidity, PI, VI, and entropy deficit in both the
ITR and GNR, indicating that dust impacts are independent on SST.

For the TC genesis parameters, the low-level vorticity (Fig. S13) is higher with the fine-resolution model in the North Atlantic region and along West African coast. The patterns in the midlevel moisture, vertical wind shear, and entropy deficit simulated with the finer resolution are similar to those from the coarse-resolution simulations (Figs. S14-S16).

\section{Conclusions}

In this study, the simulations using the Community Atmospheric Model, version 5.1, (CAM5.1) are performed over a 5-yr period (2002-06). Two scenarios are set up with and without the dust emission from the Sahara. Our analyses are focused on the influences of Saharan dust on the Atlantic regional climate and its implications for TCs in 2005 and 2006. The simulated 
(a) VI DUST 2005



(c) VI DUST 2006

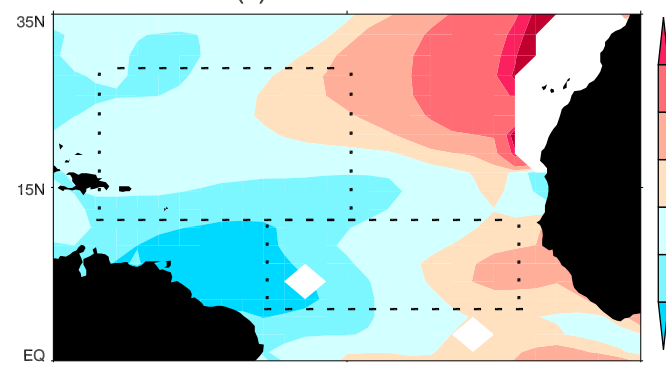

(e) VI D05-D06

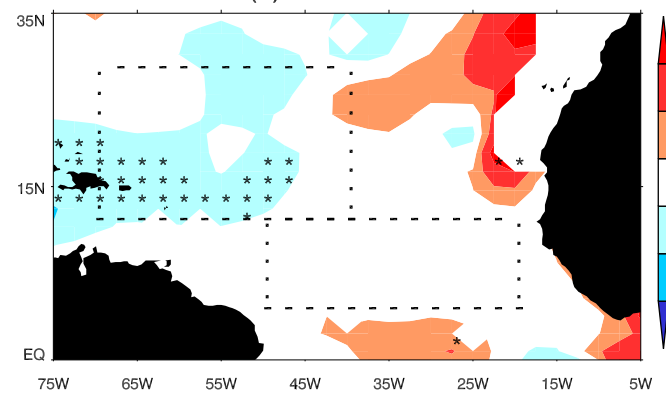

(b) VI D05-ND05

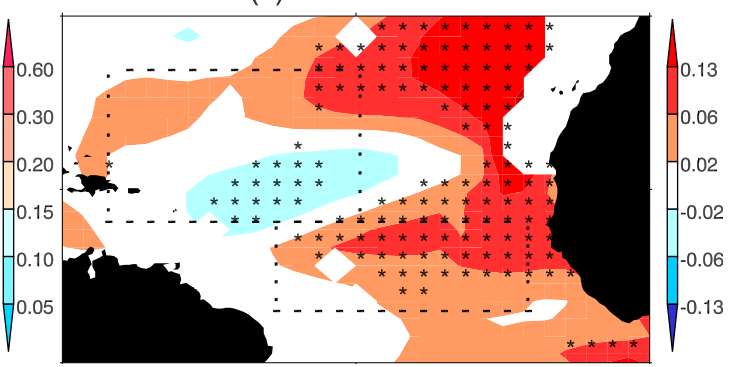

(d) VI D06-ND06

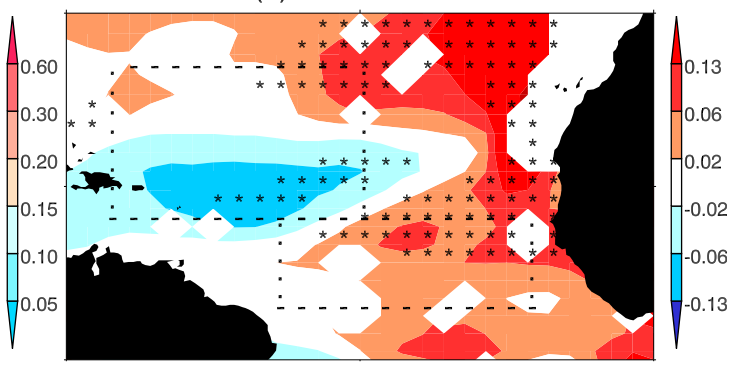

(f) VI ND05-ND06

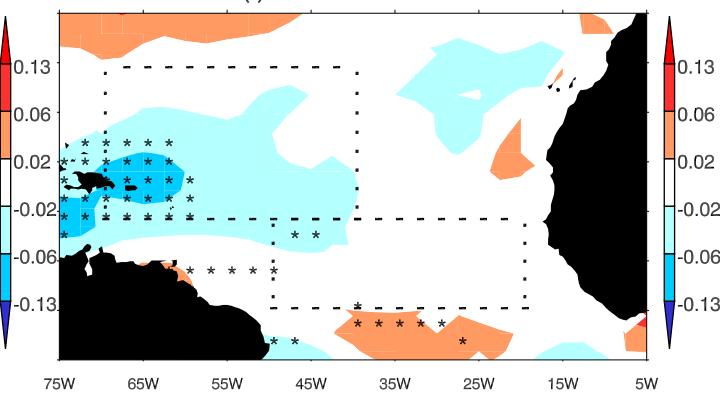

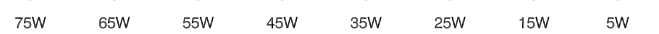

FIG. 16. As in Fig. 3, but for the ventilation index in August 2005 and 2006.

AOD and precipitation are comparable with the satellite observations.

Comparisons between the dust and nondust simulations indicate that dust plays a substantial role in the regional climate of West Africa and the North Atlantic by intensifying the SHL over the heavy dust-loaded region (north of $15^{\circ} \mathrm{N}$ ) and shifting the AEJ and the ITCZ northward. The perturbation of the large-scale flow redistributes clouds and further modifies radiative fluxes. Also, dust decreases the regional radiative energy in the atmosphere. Dust fosters a more favorable environment for the genesis of TCs by increasing the midlevel moisture and decreasing the entropy deficit in the GNR. On the other hand, dust creates unfavorable conditions for TC activities through the increased vertical wind shear and decreased low-level vorticity and PI, especially in the GNR. In the ITR, dust favors TC development by decreasing the vertical wind shear and increasing the midlevel moisture, but suppresses TC by decreasing PI.
Overall, there is an increased VI in the GNR but a decreased VI in the ITR. Hence, the dust effects increase (decrease) the TC activities in the ITR (GNR). Also, the region of TC genesis is shifted northward because of the northward movement of the convergence zone.

Comparison of the simulations between 2005 and 2006 reveals a higher precipitation rate, high cloud fraction, specific humidity, PI, and VI, but lower surface net radiative flux, wind shear, and entropy deficit in 2005, attributable to warmer SST (Fig. S7). However, there are insignificant differences in the low cloud fraction and the low-level vorticity between the two years. The conditions of higher specific humidity, PI, VI, lower wind shear, and entropy deficit are favorable for TC activities in 2005.

By comparing the SST and dust impacts, we find that dust significantly decreases the convective precipitation rate in the mid-Atlantic, shifts the ITCZ northward, increases the onshore low cloud and low cloud fraction over West Africa, and decreases the high cloud fraction 
along $15^{\circ} \mathrm{N}$ and in the mid-Atlantic, indicating robust dust impacts on the regional climate. On the other hand, the impacts of dust on the large-scale precipitation rate are dependent on SST. Overall, dust amplifies the impacts of warm SST by reducing the surface radiative flux along $10^{\circ} \mathrm{N}$ over the east Atlantic, wind shear in the ITR, and entropy deficit in the GNR. On the other hand, dust dampens the warm-SST-induced large-scale and convective precipitation increase over the west Atlantic, with a high cloud fraction increase over the eastern Caribbean along $10^{\circ} \mathrm{N}$ and specific humidity decrease at $925 \mathrm{hPa}$ north of $20^{\circ} \mathrm{N}$ over the east Atlantic.

Future studies using a vertically and horizontally highresolution model configuration are necessary to more realistically simulate the tropical cyclones. To alleviate both the resolution deficiency and computing expense for long-term simulations in global climate models, the use of high-resolution regional model simulations is an efficient approach to investigate the detailed dust microphysical processes on the genesis and development of individual tropical cyclones. In addition, the combined effects of dust dimming on SST and the ocean feedback need to be assessed using high-resolution atmosphere-ocean coupled models, although it is challenging to evaluate the interannual variabilities on a short time scale. Additional model sensitivity studies of the dust radiative properties over West Africa and the east Atlantic are also necessary.

Acknowledgments. Yuan Wang and Jonathan Jiang acknowledge the support from NASA ROSES ACMAP and CCST, and they also thank the support from the Jet Propulsion Laboratory, California Institute of Technology, under contract by NASA. Helpful discussions with Drs. William K. Lau, Robert Korty, and Yang Nan were greatly appreciated. The supercomputing computational facilities at the Texas A\&M University were employed in this research. The authors would like to thank three anonymous reviewers and editor Dr. Karen Shell for their enormous help and advice on this manuscript.

\section{REFERENCES}

Adler, R. F., and Coauthors, 2003: The version-2 Global Precipitation Climatology Project (GPCP) monthly precipitation analysis (1979-present). J. Hydrometeor., 4, 1147-1167, https://doi.org/ 10.1175/1525-7541(2003)004<1147:TVGPCP > 2.0.CO;2.

Arguez, A., A. M. Waple, and A. M. Sanchez-Lugo, 2007: State of the climate in 2006. Bull. Amer. Meteor. Soc., 88, 929-932, https://doi.org/10.1175/BAMS-88-6-929.

Beven, J. L., and Coauthors, 2008: Atlantic hurricane season of 2005. Mon. Wea. Rev., 136, 1109-1173, https://doi.org/10.1175/ 2007MWR2074.1.
Bister, M., and K. A. Emanuel, 2002: Low frequency variability of tropical cyclone potential intensity 1 . Interannual to interdecadal variability. J. Geophys. Res., 107, 4801, https://doi.org/10.1029/ 2001JD000776.

Bond, T. C., E. Bhardwaj, R. Dong, R. Jogani, S. Jung, C. Roden, D. G. Streets, and N. M. Trautmann, 2007: Historical emissions of black and organic carbon aerosol from energy related combustion, 1850-2000. Global Biogeochem. Cycles, 21, GB2018, https://doi.org/10.1029/2006GB002840.

Bracken, W. E., and L. F. Bosart, 2000: The role of synoptic-scale flow during tropical cyclogenesis over the North Atlantic Ocean. Mon. Wea. Rev., 128, 353-376, https://doi.org/10.1175/ 1520-0493(2000)128<0353:TROSSF $>2.0$. CO;2.

Bretl, S., P. Reutter, C. C. Raible, S. Ferrachat, C. S. Poberaj, L. E. Revell, and U. Lohmann, 2015: The influence of absorbed solar radiation by Saharan dust on hurricane genesis. J. Geophys. Res. Atmos., 120, 1902-1917, https://doi.org/ 10.1002/2014JD022441.

CALIPSO Science Team, 2015: CALIPSO/CALIOP level 3, lidar all-sky data, version 3.00 (subset CAL_LID_L3_APro_AllSkyStandard-V3-00). NASA Atmospheric Science Data Center (ASDC), accessed August 2017, https://doi.org/10.5067/CALIOP/ CALIPSO/CAL_LID_L3_APro_AllSky-Standard-V3-00.

Carlson, T. N., and S. G. Benjamin, 1980: Radiative heating rates for Saharan dust. J. Atmos. Sci., 37, 193-213, https://doi.org/ 10.1175/1520-0469(1980)037<0193:RHRFSD > 2.0.CO;2.

Chen, S.-H., S.-H. Wang, and M. Waylonis, 2010: Modification of Saharan air layer and environmental shear over the eastern Atlantic Ocean by dust-radiation effects. J. Geophys. Res., 115, D21202, https://doi.org/10.1029/2010JD014158.

Chen, T.-C., and H. van Loon, 1987: Interannual variation of the tropical easterly jet. Mon. Wea. Rev., 115, 1739-1759, https:/doi.org/ 10.1175/1520-0493(1987)115<1739:IVOTTE >2.0.CO;2.

Colarco, P. R., E. P. Nowottnick, C. A. Randles, B. Yi, P. Yang, K.- M. Kim, J. A. Smith, and C. G. Bardeen, 2014: Impact of radiatively interactive dust aerosols in the NASA GEOS-5 climate model: Sensitivity to dust particle shape and refractive index. J. Geophys. Res. Atmos., 119, 753-786, https://doi.org/ 10.1002/2013JD020046.

Cziczo, D. J., D. M. Murphy, P. K. Hudson, and D. S. Thomson, 2004: Single particle measurements of the chemical composition of cirrus ice residue during CRYSTAL-FACE. J. Geophys. Res., 109, D04201, https://doi.org/10.1029/2003JD004032.

d'Almeida, G. A., 1986: A model for Saharan dust transport. J. Climate Appl. Meteor., 25, 903-916, https://doi.org/10.1175/ 1520-0450(1986)025<0903:AMFSDT>2.0.CO;2.

DeMott, P. J., D. J. Cziczo, A. J. Prenni, D. M. Murphy, S. M. Kreidenweis, D. S. Thomson, R. Borys, and D. C. Rogers, 2003: Measurements of the concentration and composition of nuclei for cirrus formation. Proc. Natl. Acad. Sci. USA, 100, 14 655-14 660, https://doi.org/10.1073/pnas.2532677100.

Easter, R. C., and Coauthors, 2004: MIRAGE: Model description and evaluation of aerosols and trace gases. J. Geophys. Res., 109, D20210, https://doi.org/10.1029/2004JD004571.

Emanuel, K., and D. S. Nolan, 2004: Tropical cyclone activity and the global climate system. 26th Conf. on Hurricanes and Tropical Meteorology, Miami, FL. Amer. Meteor. Soc., 240-241, https://ams.confex.com/ams/26HURR/techprogram/ paper_75463.htm.

Emmons, L. K., and Coauthors, 2010: Description and evaluation of the Model for Ozone and Related Chemical Tracers, version 4 (MOZART-4). Geosci. Model Dev., 3, 43-67, https:// doi.org/10.5194/gmd-3-43-2010. 
Evan, A. T., J. Dunion, J. A. Foley, A. K. Heidinger, and C. S. Velden, 2006: New evidence for a relationship between Atlantic tropical cyclone activity and African dust outbreaks. Geophys. Res. Lett., 33, L19813, https://doi.org/10.1029/ 2006 GL026408.

Fan, J. W., R. Zhang, G. Li, and W.-K. Tao, 2007a: Effects of aerosols and relative humidity on cumulus clouds. J. Geophys. Res., 112, D14204, https://doi.org/10.1029/2006JD008136.

$-, \ldots,-, \ldots$, and X. Li, 2007b: Simulations of cumulus clouds using a spectral microphysics cloud-resolving model. J. Geophys. Res., 112, D04201, https://doi.org/10.1029/ 2006JD007688.

- — - W.-K. Tao, and K. Mohr, 2008: Effects of aerosol optical properties on deep convective clouds and radiative forcing. J. Geophys. Res., 113, D08209, https://doi.org/10.1029/ 2007JD009257.

—_, and Coauthors, 2014: Aerosol impacts on California winter clouds and precipitation during CalWater 2011: Local pollution versus long-range transported dust. Atmos. Chem. Phys., 14, 81-101, https://doi.org/10.5194/acp-14-81-2014.

Franklin, J. L., and D. P. Brown, 2008: Atlantic hurricane season of 2006. Mon. Wea. Rev., 136, 1174-1200, https://doi.org/10.1175/ 2007MWR2377.1.

Ghan, S. J., and R. A. Zaveri, 2007: Parameterization of optical properties for hydrated internally mixed aerosol. J. Geophys. Res., 112, D10201, https://doi.org/10.1029/2006JD007927.

—, X. Liu, R. C. Easter, R. Zaveri, P. J. Rasch, J. H. Yoon, and B. Eaton, 2012: Toward a minimal representation of aerosols in climate models: Comparative decomposition of aerosol direct, semidirect, and indirect radiative forcing. J. Climate, $\mathbf{2 5}$, 6461-6476, https://doi.org/10.1175/JCLI-D-11-00650.1.

Ginoux, P., J. M. Prospero, T. E. Gill, N. C. Hsu, and M. Zhao, 2012: Global-scale attribution of anthropogenic and natural dust sources and their emission rates based on MODIS Deep Blue aerosol products. Rev. Geophys., 50, RG3005, https:// doi.org/10.1029/2012RG000388.

Gray, W. M., 1998: The formation of tropical cyclones. Meteor. Atmos. Phys., 67, 37-69, https://doi.org/10.1007/BF01277501.

Grini, A., and C. S. Zender, 2004: Roles of saltation, sandblasting, and wind speed variability on mineral dust aerosol size distribution during the Puerto Rican Dust Experiment (PRIDE). J. Geophys. Res., 109, D07202, https://doi.org/10.1029/2003JD004233.

Guan, X., J. Huang, Y. Zhang, Y. Xie, and J. Liu, 2016: The relationship between anthropogenic dust and population over global semi-arid regions. Atmos. Chem. Phys., 16, 5159-5169, https://doi.org/10.5194/acp-16-5159-2016.

Hess, M. M., P. P. Koepke, and I. I. Schult, 1998: Optical properties of aerosols and clouds: The software package OPAC. Bull. Amer. Meteor. Soc., 79, 831-844, https://doi.org/ 10.1175/1520-0477(1998)079<0831:OPOAAC $>2.0 . C O ; 2$.

Huang, J., T. Wang, W. Wang, Z. Li, and H. Yan, 2014: Climate effects of dust aerosols over East Asian arid and semiarid regions. J. Geophys. Res. Atmos., 119, 11398-11416, https:// doi.org/10.1002/2014JD021796.

Huang, X., Y. Song, C. Zhao, X. Cai, H. Zhang, and T. Zhu, 2015: Direct radiative effect by multicomponent aerosol over China. J. Climate, 28, 3472-3495, https://doi.org/10.1175/JCLI-D-14-00365.1.

Huneeus, N., and Coauthors, 2011: Global dust model intercomparison in AeroCom phase I. Atmos. Chem. Phys., 11, 7781-7816, https://doi.org/10.5194/acp-11-7781-2011.

IPCC, 2013: Climate Change 2013: The Physical Science Basis. T. F. Stocker et al., Eds., Cambridge University Press, 1535 pp., https://doi.org/10.1017/CBO9781107415324.
Junker, C., and C. Liousse, 2008: A global emission inventory of carbonaceous aerosol from historic records of fossil fuel and biofuel consumption for the period 1860-1997. Atmos. Chem. Phys., 8, 1195-1207, https://doi.org/10.5194/acp-8-1195-2008.

Karydis, V., P. Kumar, D. Barahona, I. Sokolik, and A. Nenes, 2011: On the effect of dust particles on global cloud condensation nuclei and cloud droplet number. J. Geophys. Res., 116, D23204, https://doi.org/10.1029/2011JD016283.

Kaufman, Y. J., I. Koren, L. A. Remer, D. Tanré, P. Ginoux, and S. Fan, 2005: Dust transport and deposition observed from the Terra-Moderate Resolution Imaging Spectroradiometer (MODIS) spacecraft over the Atlantic Ocean. J. Geophys. Res., 110, D10S12, https://doi.org/10.1029/2003JD004436.

Kim, K.-M., W. K.-M. Lau, Y. C. Sud, and G. K. Walker, 2010: Influence of aerosol-radiative forcings on the diurnal and seasonal cycles of rainfall over West Africa and eastern Atlantic Ocean using GCM simulations. Climate Dyn., 35, 115126, https://doi.org/10.1007/s00382-010-0750-1.

Lafore, J.-P., and Coauthors, 2011: Progress in understanding of weather systems in West Africa. Atmos. Sci. Lett., 12, 7-12, https://doi.org/10.1002/asl.335.

Lamarque, J.-F., and Coauthors, 2010: Historical (1850-2000) gridded anthropogenic and biomass burning emissions of reactive gases and aerosols: Methodology and application. Atmos. Chem. Phys., 10, 7017-7039, https://doi.org/10.5194/acp-10-7017-2010.

Lau, K.-M., and K.-M. Kim, 2007a: How nature foiled the 2006 hurricane forecasts. Eos, Trans. Amer. Geophys. Union, 88, 105-107, https://doi.org/10.1029/2007EO090002.

— Geophys. Res. Lett., 34, L23811, https://doi.org/10.1029/ 2007 GL031538.

_- M. K. Kim, and K. M. Kim, 2006: Asian summer monsoon anomalies induced by aerosol direct forcing: The role of the Tibetan Plateau. Climate Dyn., 26, 855-864, https://doi.org/ 10.1007/s00382-006-0114-z.

— , K. M. Kim, Y. C. Sud, and G. K. Walker, 2009: A GCM study of the response of the atmospheric water cycle of West Africa and the Atlantic to Saharan dust radiative forcing. Ann. Geophys., 27, 4023-4037, https://doi.org/10.5194/ angeo-27-4023-2009.

Levin, Z., E. Ganor, and V. Gladstein, 1996: The effects of desert particles coated with sulfate on rain formation in the eastern Mediterranean. J. Appl. Meteor., 35, 1511-1523, https://doi.org/ 10.1175/1520-0450(1996)035<1511:TEODPC > 2.0.CO;2.

Li, G., Y. Wang, K.-H. Lee, Y. Diao, and R. Zhang, 2008a: Increased winter precipitation over the North Pacific from 19841994 to 1995-2005 inferred from the Global Precipitation Climatology Project. Geophys. Res. Lett., 35, L13821, https:// doi.org/10.1029/2008GL034668.

$\ldots, \ldots$, and R. Zhang, 2008b: Implementation of a two-moment bulk microphysics scheme to the WRF model to investigate aerosol-cloud interaction. J. Geophys. Res., 113, D15211, https://doi.org/10.1029/2007JD009361.

$\longrightarrow,-1$, K.-H. Lee, Y. Diao, and R. Zhang, 2009: Impacts of aerosols on development and precipitation of a mesoscale squall line. J. Geophys. Res., 114, D17205, https://doi.org/ 10.1029/2008JD011581.

Lin, Y., Y. Wang, B. Pan, J. Hu, Y. Liu, and R. Zhang, 2016: Distinct impacts of aerosols on an evolving continental cloud complex during the RACORO field campaign. J. Atmos. Sci., 73, 3681-3700, https://doi.org/10.1175/JAS-D-15-0361.1.

Liu, X., J. E. Penner, S. J. Ghan, and M. Wang, 2007: Inclusion of ice microphysics in the NCAR Community Atmospheric 
Model version 3 (CAM3). J Climate, 20, 4526-4547, https:// doi.org/10.1175/JCLI4264.1.

_ _ and Coauthors, 2012: Toward a minimal representation of aerosols in climate models: Description and evaluation in the Community Atmosphere Model CAM5. Geosci. Model Dev., 5, 709-739, https://doi.org/10.5194/gmd-5-709-2012.

Logan, T., B. Xi, and X. Dong, 2014: Aerosol properties and their influences on marine boundary layer cloud condensation nuclei at the ARM mobile facility over the Azores. J. Geophys. Res. Atmos., 119, 4859-4872, https://doi.org/10.1002/ 2013JD021288.

Lohmann, U., 2002: Possible aerosol effects on ice clouds via contact nucleation. J. Atmos. Sci., 59, 647-656, https://doi.org/ 10.1175/1520-0469(2001)059<0647:PAEOIC $>2.0 . C O ; 2$.

Mahowald, N., M. Yoshioka, W. D. Collins, A. J. Conley, D. W. Fillmore, and D. B. Coleman, 2006: Climate response and radiative forcing from mineral aerosols during the Last Glacial Maximum, pre-industrial, current and doubled-carbon dioxide climates. Geophys. Res. Lett., 33, L20705, https://doi.org/ 10.1029/2006GL026126.

_ , S. Albani, J. F. Kok, S. Engelstaeder, R. Scanza, D. S. Ward, and M. G. Flanner, 2014: The size distribution of desert dust aerosols and its impact on the Earth system. Aeolian Res., 15, 53-71, https://doi.org/10.1016/j.aeolia.2013.09.002.

Mårtensson, E. M., E. D. Nilsson, G. de Leeuw, L. H. Cohen, and H.-C. Hansson, 2003: Laboratory simulations and parameterization of the primary marine aerosol production. J. Geophys. Res., 108, 4297, https://doi.org/10.1029/ 2002JD002263.

Meyers, M. P., P. J. Demott, and W. R. Cotton, 1992: New primary ice-nucleation parameterizations in an explicit cloud model. J. Appl. Meteor., 31, 708-721, https://doi.org/10.1175/ 1520-0450(1992)031<0708:NPINPI >2.0.CO;2.

Miller, R. L., and I. Tegen, 1998: Climate response to soil dust aerosols. J. Climate, 11, 3247-3267, https://doi.org/10.1175/ 1520-0442(1998)011<3247:CRTSDA > 2.0.CO;2.

Morrison, H., and A. Gettelman, 2008: A new two-moment bulk stratiform cloud microphysics scheme in the Community Atmosphere Model, version 3 (CAM3). Part I: Description and numerical tests. J. Climate, 21, 3642-3659, https://doi.org/ 10.1175/2008JCLI2105.1.

Neale, R. B., J. H. Richter, and M. Jochum, 2008: The impact of convection on ENSO: From a delayed oscillator to a series of events. J. Climate, 21, 5904-5924, https://doi.org/10.1175/ 2008JCLI2244.1.

_ - and Coauthors, 2010: Description of the NCAR Community Atmosphere Model (CAM 5.0). NCAR Tech. Note NCAR/TN486+STR, 274 pp., http://www.cesm.ucar.edu/models/cesm1.0/ cam/docs/description/cam5_desc.pdf.

Nesbitt, S. W., R. Zhang, and R. E. Orville, 2000: Seasonal and global $\mathrm{NO}_{\mathrm{x}}$ production by lightning estimated from the Optical Transient Detector (OTD). Tellus, 52B, 1206-1215, https://doi.org/10.3402/tellusb.v52i5.17098.

Nowottnick, E., P. Colarco, A. da Silva, D. Hlavka, and M. McGill, 2011: The fate of Saharan dust across the Atlantic and implications for a Central American dust barrier. Atmos. Chem. Phys., 11, 8415-8431, https://doi.org/10.5194/ acp-11-8415-2011.

Orville, R. E., and Coauthors, 2001: Enhancement of cloud-toground lightning over Houston, Texas. Geophys. Res. Lett., 28 2597-2600, https://doi.org/10.1029/2001GL012990.

Park, S., and C. S. Bretherton, 2009: The University of Washington shallow convection and moist turbulence schemes and their impact on climate simulations with the Community Atmosphere Model. J. Climate, 22, 3449-3469, https://doi.org/ 10.1175/2008JCLI2557.1.

,-- , and P. J. Rasch, 2014: Integrating cloud processes in the Community Atmosphere Model, version 5. J. Climate, 27, 6821-6856, https://doi.org/10.1175/JCLI-D-14-00087.1

Peng, J. F., and Coauthors, 2016: Markedly enhanced absorption and direct radiative forcing of black carbon under polluted urban environments. Proc. Natl. Acad. Sci. USA, 113, 42664271, https://doi.org/10.1073/pnas.1602310113.

Platnick, S., and Coauthors, 2015: MODIS Atmosphere L3 Monthly Product. NASA MODIS Adaptive Processing System, Goddard Space Flight Center, accessed January 2016, https:// doi.org/10.5067/MODIS/MOD08_M3.006.

Posselt, R., and U. Lohmann, 2008: Influence of giant CCN on warm rain processes in the ECHAM5 GCM. Atmos. Chem. Phys., 8, 3769-3788, https://doi.org/10.5194/acp-8-3769-2008.

Prenni, A. J., and Coauthors, 2009: Relative roles of biogenic emissions and Saharan dust as ice nuclei in the Amazon basin. Nat. Geosci., 2, 402-405, https://doi.org/10.1038/ngeo517.

Prospero, J. M., and T. N. Carlson, 1970: Radon-222 in North Atlantic trade winds: Its relationship to dust transport from Africa. Science, 167, 974-977, https://doi.org/10.1126/science.167.3920.974.

Randles, C. A., P. R. Colarco, and A. Da Silva, 2013: Direct and semi-direct aerosol effects in the NASA GEOS-5 AGCM: Aerosol-climate interactions due to prognostic versus prescribed aerosols. J. Geophys. Res. Atmos., 118, 149-169, https://doi.org/10.1029/2012JD018388.

Reale, O., K. M. Lau, A. da Silva, and T. Matsui, 2014: Impact of assimilated and interactive aerosol on tropical cyclogenesis. Geophys. Res. Lett., 41, 3282-3288, https://doi.org/10.1002/ 2014GL059918.

Rosenfeld, D., and R. Nirel, 1996: Seeding effectiveness-The interaction of desert dust and the southern margins of rain cloud systems in Israel. J. Appl. Meteor., 35, 1502-1510, https://doi.org/ 10.1175/1520-0450(1996)035<1502:SEIODD > 2.0.CO;2.

- Y. Rudich, and R. Lahav, 2001: Desert dust suppressing precipitation: A possible desertification feedback loop. Proc. Natl. Acad. Sci. USA, 98, 5975-5980, https://doi.org/10.1073/ pnas.101122798.

- U. Lohmann, G. B. Raga, C. D. O'Dowd, M. Kulmala, S. Fuzzi, A. Reissell, and M. O. Andreae, 2008: Flood or drought: How do aerosols affect precipitation? Science, 321, 1309-1313, https://doi.org/10.1126/science.1160606.

, W. L. Woodley, A. Khain, W. R. Cotton, G. Carrió, I. Ginis, and J. H. Golden, 2012: Aerosol effects on microstructure and intensity of tropical cyclones. Bull. Amer. Meteor. Soc., 93, 987-1001, https://doi.org/10.1175/BAMS-D-11-00147.1.

Schepanski, K., I. Tegen, and A. Macke, 2009: Saharan dust transport and deposition towards the tropical northern Atlantic. Atmos. Chem. Phys., 9, 1173-1189, https://doi.org/ 10.5194/acp-9-1173-2009.

Seigel, R. B., S. C. van den Heever, and S. M. Saleeby, 2013: Mineral dust indirect effects and cloud radiative feedbacks of a simulated idealized nocturnal squall line. Atmos. Chem. Phys., 13, 4467-4485, https://doi.org/10.5194/acp-13-4467-2013.

Shao, Y., and Coauthors, 2011: Dust cycle: An emerging core theme in Earth system science. Aeolian Res., 2, 181-204, https://doi.org/10.1016/j.aeolia.2011.02.001.

Smith, S. J., H. Pitcher, and T. M. L. Wigley, 2001: Global and regional anthropogenic sulfur dioxide emissions. Global Planet. Change, 29, 99-119, https://doi.org/10.1016/ S0921-8181(00)00057-6. 
_ R. Andres, E. Conception, and J. Lurz, 2004: Historical sulfur dioxide emissions 1850-2000: Methods and results. Tech. Rep. PNNL-14537, Pacific Northwest National Laboratory, Joint Global Change Research Institute, 14 pp.

Strong, J. D. O., G. A. Vecchi, and P. Ginoux, 2015: The response of the tropical Atlantic and West African climate to Saharan dust in a fully coupled GCM. J. Climate, 28, 7071-7092, https:// doi.org/10.1175/JCLI-D-14-00797.1.

Tang, B., and K. Emanuel, 2012: A ventilation index for tropical cyclones. Bull. Amer. Meteor., 93, 1901-1912, https://doi.org/ 10.1175/BAMS-D-11-00165.1.

van den Heever, S. C., G. G. Carrió, W. R. Cotton, P. J. DeMott, and A. J. Prenni, 2006: Impacts of nucleating aerosol on Florida storms. Part I: Mesoscale simulations. J. Atmos. Sci., 63, 1752-1775, https://doi.org/10.1175/JAS3713.1.

Wang, Y., 2015: Aerosol-Cloud Interactions from Urban, Regional, to Global Scales. Springer Theses, Springer, $86 \mathrm{pp}$.

—, Q. Wan, W. Meng, F. Liao, H. Tan, and R. Zhang, 2011: Longterm impacts of aerosols on precipitation and lightning over the Pearl River Delta megacity area in China. Atmos. Chem. Phys., 11, 12 421-12 436, https://doi.org/10.5194/acp-11-12421-2011.

—, J. Fan, R. Zhang, L. R. Leung, and C. Franklin, 2013: Improving bulk microphysics parameterizations in simulations of aerosol effects. J. Geophys. Res. Atmos., 118, 5361-5379, https://doi.org/10.1002/jgrd.50432.

— aerosols on Pacific storm track using a multiscale global climate model. Proc. Natl. Acad. Sci. USA, 111, 6894-6899, https://doi.org/10.1073/pnas.1403364111.

, R. Zhang, and R. Saravanan, 2014b: Asian pollution climatically modulates mid-latitude cyclones following hierarchical modeling and observational analysis. Nat. Commun., 5, 3098, https://doi.org/10.1038/ncomms4098.

— , K.-H. Lee, Y. Lin, M. Levy, and R. Zhang, 2014c: Distinct effects of anthropogenic aerosols on tropical cyclones. Nat. Climate Change, 4, 368-373, https://doi.org/10.1038/nclimate2144.

_ , P. L. Ma, J. H. Jiang, H. Su, and P. J. Rasch, 2016: Toward reconciling the influence of atmospheric aerosols and greenhouse gases on light precipitation changes in eastern China. J. Geophys. Res. Atmos., 121, 5878-5887, https://doi.org/ 10.1002/2016JD024845.

_ J. Jiang, H. Su, S. Choi, L. Huang, J. Guo, and Y. Yung, 2018: Elucidating the role of anthropogenic aerosols in Arctic sea ice variations. J. Climate, 31, 99-114, https://doi.org/10.1175/ JCLI-D-17-0287.1.

Wilcox, E. M., K. M. Lau, and K. M. Kim, 2010: A northward shift of the North Atlantic Ocean intertropical convergence zone in response to summertime Saharan dust outbreaks. Geophys. Res. Lett., 37, L04804, https://doi.org/10.1029/2009GL041774.

Willoughby, H. E., D. P. Jorgensen, R. A. Black, and S. L. Rosenthal, 1985: Project STORMFURY-A scientific chronicle 1962-1983. Bull. Amer. Meteor. Soc., 66, 505-514, https:// doi.org/10.1175/1520-0477(1985)066<0505:PSASC >2.0.CO;2.

Winker, D. M., M. A. Vaughan, A. Omar, Y. Hu, K. A. Powell, Z. Liu, W. H. Hunt, and S. A. Young, 2009: Overview of the CALIPSO mission and CALIOP data processing algorithms. J. Atmos. Oceanic Technol., 26, 2310-2323, https://doi.org/ 10.1175/2009JTECHA1281.1.

Wong, S., A. E. Dessler, N. M. Mahowald, P. R. Colarco, and A. da Silva, 2008: Long-term variability in Saharan dust transport and its link to North Atlantic sea surface temperature. Geophys. Res. Lett., 35, L07812, https://doi.org/10.1029/2007GL032297.
P. Yang, and Q. Feng, 2009: Maintenance of lower tropospheric temperature inversion in the Saharan air layer by dust and dry anomaly. J. Climate, 22, 5149-5162, https:// doi.org/10.1175/2009JCLI2847.1.

Wu, G. X., and Coauthors, 2016: Advances in studying interactions between aerosols and monsoon in China. Sci. China Earth Sci., 59, 1-16, https://doi.org/10.1007/s11430-015-5198-z.

Yin, Y., Z. Levin, T. G. Reisin, and S. Tzivion, 2000: The effects of giant cloud condensation nuclei on the development of precipitation in convective clouds-A numerical study. Atmos. Res., 53, 91-116, https://doi.org/10.1016/S0169-8095(99)00046-0.

Yoshioka, M., N. M. Mahowald, A. J. Conley, W. D. Collins, D. W. Fillmore, C. S. Zender, and D. B. Coleman, 2007: Impact of desert dust radiative forcing on Sahel precipitation: Relative importance of dust compared to sea surface temperature variations, vegetation changes, and greenhouse gas warming. J. Climate, 20, 1445-1467, https://doi.org/10.1175/JCLI4056.1.

Young, K. C., 1974: The role of contact nucleation in ice phase initiation in clouds. J. Atmos. Sci., 31, 768-776, https://doi.org/ 10.1175/1520-0469(1974)031<0768:TROCNI > 2.0.CO;2.

Yuan, T., Z. Li, R. Zhang, and J. Fan, 2008: Increase of cloud droplet size with aerosol optical depth: An observation and modeling study. J. Geophys. Res., 113, D04201, https://doi.org/ 10.1029/2007JD008632.

Zehr, R. M., 1992: Tropical cyclogenesis in the western North Pacific. NOAA Tech. Rep. NESDIS 61, 181 pp.

Zender, C. S., H. S. Bian, and D. Newman, 2003: Mineral Dust Entrainment and Deposition (DEAD) model: Description and 1990s dust climatology. J. Geophys. Res., 108, 4416, https:// doi.org/10.1029/2002JD002775.

_ _ R. Miller, and I. Tegen, 2004: Quantifying mineral dust mass budgets: Terminology, constraints, and current estimates. Eos, Trans. Amer. Geophys. Union, 85, 509-512, https://doi.org/ 10.1029/2004EO480002.

Zhang, G. J., and N. A. McFarlane, 1995: Sensitivity of climate simulations to the parameterization of cumulus convection in the $\mathrm{Ca}$ nadian Climate Center general circulation model. Atmos.-Ocean, 33, 407-446, https://doi.org/10.1080/07055900.1995.9649539.

Zhang, H., G. M. McFarquhar, S. M. Saleeby, and W. R. Cotton, 2007: Impacts of Saharan dust as CCN on the evolution of an idealized tropical cyclone. Geophys. Res. Lett., 34, L14812, https://doi.org/10.1029/2007GL029876.

W. R. Cotton, and Y. Deng, 2009: Direct and indirect impacts of Saharan dust acting as cloud condensation nuclei on tropical cyclone eyewall development. Geophys. Res. Lett., 36, L06802, https://doi.org/10.1029/2009GL037276.

Zhang, R. Y., G. H. Li, J. W. Fan, D. L. Wu, and M. J. Molina, 2007: Intensification of Pacific storm track linked to Asian pollution. Proc. Natl. Acad. Sci. USA, 104, 5295-5299, https://doi.org/ 10.1073/pnas.0700618104.

— , and Coauthors, 2015: Formation of urban fine particulate matter. Chem. Rev., 115, 3803-3855, https://doi.org/10.1021/ acs.chemrev.5b00067.

Zhao, C., X. Liu, L. R. Leung, and S. Hagos, 2011: Radiative impact of mineral dust on monsoon precipitation variability over West Africa. Atmos. Chem. Phys., 11, 1879-1893, https:// doi.org/10.5194/acp-11-1879-2011.

— , and Coauthors, 2013: A sensitivity study of radiative fluxes at the top of atmosphere to cloud-microphysics and aerosol parameters in the Community Atmosphere Model CAM5. Atmos. Chem. Phys., 13, 10 969-10 987, https://doi.org/10.5194/ acp-13-10969-2013. 